\title{
Gentilicios y seudogentilicios: mostración vs. descripción
}

\author{
MARCIAL MORERA \\ Universidad de La Laguna
}

Como todo ente existente, sea real o imaginario, las personas naturales de un lugar determinado pueden designarse en español de dos formas radicalmente distintas, aunque complementarias:

De un lado, pueden designarse de forma mostrativa o identificadora, mediante un adjetivo de relación derivado del nombre propio del lugar en que nacieron. Así tenemos que los naturales de Soria son sorianos, los naturales de Guantánamo, guantanameros, los naturales de Egipto, egipcios, los naturales de Borgoña, borgoñones, los naturales de Noruega, noruegos, los naturales de La Gomera, gomeros, y los naturales de Barro, en Pontevedra, barrosos. Es lo que la tradición lingüística suele denominar adjetivos gentilicios, que «denotan la procedencia geográfica de la persona o su nacionalidad», como dice la Academia ${ }^{1}$.

¿Qué caracteriza exactamente la significación invariante de estas particulares unidades idiomáticas? Dos cosas distintas: a) Un nombre propio de base, que designa un lugar determinado. En el caso concreto de nuestros ejemplos, Soria, Guantánamo, Egipto, Borgoña, Noruega, La Gomera y Barro; y b) Una adjetivación de ese nombre propio, que puede realizarse de dos formas distintas: ba) De forma inmediata, sin ninguna marca morfológica. En nuestros ejemplos: Noruega $\rightarrow$ noruego, La Gomera $\rightarrow$ gomero; y bb) De forma mediata, a través de un complemento morfológico, que expresa una determinado relación con ese nombre propio. En nuestros ejemplos: -ano (Soria $\rightarrow$ soriano), -ero (Guantánamo $\rightarrow$ guantanamero), -ío (Egipto $\rightarrow$ egipcio), -ón (Borgo$\tilde{n} a \rightarrow$ borgoñón) y -oso (Barro $\rightarrow$ barroso). Y, como los sufijos que participan en la mencionada función adjetivadora son diferentes, diferente es también la forma de significar la relación con el topónimo ${ }^{2}$. Así, el -ano de segoviano presenta el topónimo como 'lugar externamente alcanzado o abarcado'; el -ero de guantanamero, como 'ámbito del que emana activamente su materia'; el -io de egipcio, como 'emanación

\footnotetext{
* Este estudio se enmarca dentro del proyecto de investigación Estudio global de los gentilicios de la lengua española: materiales americanos, nuevas consideraciones teóricas y gestión informática de los datos (FFI 2011-26256), patrocinado por la Secretaría de Estado de Investigación, Desarrollo e Innovación del Ministerio de Economía y Competitividad del Estado español.

${ }^{1}$ He tratado de caracterizar semánticamente esta categoría de palabras en Morera (2011a y 2012).

${ }^{2}$ El problema de la frecuencia de uso de los sufijos que tienen función gentilicia ha sido considerado por Núñez (2005). El predominio de un sufijo u otro en esta función denotativa está determinado por factores diversos, entre los que destacan la fonética del topónimo, la geografía y la historia. Para el tema de las determinaciones fonéticas, vid. el viejo artículo de Sachs (1934). Para el tema de la distribución geográfica, vid. Garcés Gómez (1988). Para el tema de la formación histórica de los gentilicios españoles, vid. García Gallarín (2003).
} 
activa'; el -ón de borgoñón, como 'sustancia con límite bruscamente superado'; y el -oso de barroso, como 'materia interna' del sustantivo que lo rige ${ }^{3}$. Puede incluso ocurrir que un mismo topónimo desarrolle formas gentilicias distintas. Así, el topónimo Nájera, por ejemplo, ha desarrollado por lo menos tres gentilicios distintos: najerano, najerense y najerino, obviamente, con significación relacional diferente, a pesar de su confluencia designativa ${ }^{4}$. Lo que quiere decir que no se puede hablar de sinonimia entre los distintos sufijos que aparecen en la función textual gentilicia. Ya había señalado Bello que

a veces hay dos o más adjetivos para significar una misma nacionalidad o país, pero que sin embargo no pueden usarse promiscuamente uno por otro. Así, de los tres adjetivos árabe, arábigo y arabesco, el primero es el que siempre se sustantiva, significando los naturales de Arabia, de manera que pudiendo decirse el árabe y el arábigo por la lengua (aunque mejor a mi parecer, el primero), no se toleraría los arábigos por los árabes, hablándose de la nación; pero el más limitado en sus aplicaciones usuales es arabesco, que apenas se emplea sino como término de pintura (1981: 193-194).

Por derivar de topónimos, de nombres de una enorme profundidad histórica, en muchos casos procedentes de lenguas antiquísimas, estos adjetivos telúricos encierran siglos y hasta milenios de experiencia natural y humana. No se olvide que, como escribe Menéndez Pidal,

en los nombres de los ríos, montes y lugares escuchamos efectivamente la voz lejana de los pueblos que nos precedieron sobre nuestro suelo y que bajo él se sepultaron en inmemoriales vicisitudes históricas, porque esos nombres vienen, por densa tradición, de boca en boca, desde los labios de aquellos antepasados prehistóricos hasta nuestros oídos. La toponimia será recurso único para descubrir algo de la relación que el idioma de hoy guarda con el de nuestros antepasados más remotos (2005: 5-6).

Si tuviéramos que definir esta relación de forma general, podríamos decir, con los diccionarios al uso, que lo ella significa es algo así como 'perteneciente o relativo a' ${ }^{5}$. Así, soriano significaría 'perteneciente o relativo a ese lugar concreto (con una geografía, una gente, una flora, una fauna, una climatología, una historia, etc., determinadas) que se denomina Soria'; guantanamero, 'perteneciente o relativo a ese lugar concreto (con una geografía, una gente, una flora, una fauna, una climatología, una historia, etc., determinadas) que se denomina Guantánamo'; egipcio, 'perteneciente o relativo a ese lugar concreto (con una geografía, una gente, una flora, una fauna, una climatología,

${ }^{3}$ Una lista de los sufijos que más frecuentemente aparecen en la formación de adjetivos gentilicios puede verse en Rainer (1999). Por mi parte, he tratado la significación invariante de estos sufijos en Morera (2005). Para el problema del tratamiento de estos sufijos en el diccionario, véase Herrera Santana y Pérez Vigaray (2012). cía Padrón (en prensa)

Los problemas formales que plantea la derivación que nos ocupa han sido abordados por Gar-

${ }_{5}^{5}$ Obviamente, lo que se describe en esta paráfrasis no es la significación invariante del complemento morfológico, sino más exactamente el sentido contextual que provocan de forma general todos los sufijos que aparecen en dicha función gentilicia. La verdadera significación invariante de los derivados que desarrollan sentido gentilicio no se puede reducir a términos generales, porque cada sufijo expresa la relación de una forma semántica particular. 
una historia, etc., determinadas) que se denomina Egipto'; borgoñón, 'perteneciente o relativo a ese lugar concreto (con una geografía, una gente, una flora, una fauna, una climatología, una historia, etc., determinadas) que se denomina Borgoña'; y barroso, 'perteneciente o relativo a ese lugar concreto (con una geografía, una gente, una flora, una fauna, una climatología, una historia, etc., determinadas) que se denomina Barro, ${ }^{6}$. 'Perteneciente o relativo a' no es, pues, una acepción más del gentilicio, como 'natural de', 'producido en', 'lengua hablada en', etc., según suponen nuestros lexicógrafos, sino la significación básica de estos adjetivos de relación, de la que dichas acepciones no son otra cosa que meras orientaciones de sentido contextuales.

Internamente, no hay, por tanto, en las palabras que nos ocupan significación descriptiva o conceptual alguna, sino significación mostrativa o identificadora (o, para ser más exactos, relación con una significación mostrativa o identificadora), que es la que aporta el nombre propio de lugar de base ${ }^{7}$. Todo se reduce a indicar que la persona, animal o cosa designado por el sustantivo que rige al adjetivo gentilicio se encuentra internamente caracterizado por lo designado por el topónimo implicado ${ }^{8}$ : i. e., la adjetivación hace que el carácter identificador del topónimo pase a formar parte interna del nombre regente, imponiendo a este la naturaleza, cultura, lengua, costumbres, carácter, forma de ser, etc., que lo caracteriza. Así, gallego, por ejemplo, es aquel que tiene todas las características (cultura, lengua, costumbres, carácter, forma de ser, etc.,) propias de ese lugar determinado que se llama Galicia; gaditano, aquel que tiene todas las características (cultura, lengua, costumbres, carácter, forma de ser, etc.) de ese lugar determinado que se llama Cádiz. La relación entre el gentilicio y el nombre que lo rige no es externa, sino interna, porque llega a este como atributo. Y, como la relación que expresa el adjetivo gentilicio es interna, y no externa, no se puede decir que este signi-

${ }^{6}$ Para el problema de la variación formal de los gentilicios, vid. García Padrón (en prensa).

${ }^{7}$ Como es de sobra sabido, los nombres propios significan de forma mostrativa, exactamente igual que los tradicionalmente llamados pronombres, de los que se diferencian únicamente en lo relativo a la capacidad referencial: mientras que los pronombres son polirreferenciales, los nombres propios son unirreferenciales, designan una sola persona, un solo animal o una sola cosa, como decía la gramática tradicional. De ahí la enorme cantidad de información enciclopédica que suelen contener (Morera, 1999). De todas formas, hay que tener en cuenta que los gentilicios no son nombres propios en el sentido más estricto de la palabra, sino derivados de nombres propios, como son derivados de nombres propios (en este caso de nombres propios de persona) unamuniano, marxista o cristiano. Ni categorial ni sintácticamente se puede decir que los gentilicios sean nombres propios. Categorialmente, porque se trata de adjetivos de relación, y los adjetivos no pueden ser propios, no pueden significar de forma mostrativa. Sintácticamente, porque, cuando se sustantivan, que es cuando único podría actuar como nombres propios, se comportan como nombres comunes, como nociones generales. Por eso, si queremos determinarlos, tenemos que asociarlos a un pronombre.

${ }^{8}$ En ciertas culturas, ciertas lenguas y ciertas épocas históricas, la definición del grupo se hace en función del clan (v. gr., camita, originariamente, 'de Cam', semita, originariamente, 'de Sem', ismaelita, originariamente, 'de Ismael', etc., del hebreo antiguo) o en función del tótem que haya adoptado el grupo. En el primer caso, se define como descendiente o heredero de una estirpe humana. En el segundo, como miembro de la especie del animal, vegetal, etc., designada, y, por tanto, con los atributos que la caracterizan. «Cuando las vidas de los hombres se suponen relacionadas con ciertos animales - nos dice Frazer-, es obvio que los animales difícilmente pueden distinguirse de los hombres o los hombres de los animales. Si la vida de mi hermano Juan está en un murciélago, entonces en cierto sentido el murciélago es tan hermano mío como Juan y, por otro lado, Juan es en un sentido un murciélago, puesto que su vida está en un murciélago» (2001: 772). 
fique 'procedencia', o 'nacionalidad'. Español, por ejemplo, no significa en realidad 'de España', ni 'procedente de España', ni 'nacido en España', que son hechos más o menos episódicos o circunstanciales. Significa más bien 'que posee todas las características de España', 'que está constituido de su naturaleza, cultura, historia, etc.'. Tiempo lagunero no es 'tiempo que procede de La Laguna', sino 'tiempo que tiene las características de La Laguna'. En esta forma de ver, la tierra (fundamentalmente, el paisaje) no solo determina el alma del hombre y la peculiaridad de los animales, plantas y cosas, sino que también dicta su comportamiento. No es lo mismo un hombre de montaña que un hombre de llano o de costa, como no es lo mismo un pez de litoral que un pez de hondura. Cuando decimos que el gentilicio significa 'del lugar indicado', a secas, desvirtuamos la realidad, porque reducimos todo a la idea externa de 'movimiento de origen' expresada por la preposición de. Y lo que significa el gentilicio no es eso, sino que el sustantivo de que se trata tiene las características del topónimo implicado, o que está hecho de su materia. «El medio imprime al hombre un símbolo primario; un determinado modo de ser. Símbolo primario que irá arrastrando a lo largo de su vida», dice el poeta canario Pedro García Cabrera (2005: 20). Por eso, la paráfrasis que mejor cuadra a este tipo de adjetivos es 'que es de la condición del lugar designado'. Es lo que explica su carácter de denominación objetiva, de denominación que carece, en principio, de toda subjetividad. Se trata del nombre que corresponde a alguien por el hecho objetivo de estar investido de la condición del topónimo que nombra el lugar que habita. Por eso, suele surgir desde dentro del grupo humano designado ${ }^{9}$.

Como es de sobra sabido, la relación entre la gente y el territorio puede expresarse también mediante una construcción sintáctica, con la preposición de: v. gr., los de Londres, niños de Puerto del Rosario. Pero esta construcción preposicional no significa la relación de la misma forma que la construcción morfológica: en la fórmula analítica, la relación entre la persona y el lugar es externa, porque el nombre de lugar se presenta como 'punto de referencia independiente (sustantivo) desde el que se orienta el nombre de persona'; en la sintética, la relación es interna, como indicamos más arriba, porque el nombre de lugar se presenta como 'nota semántica simple (adjetivo) del nombre de persona'. El resultado de ello es que la construcción sintáctica tiene mucha menos fuerza caracterizadora que la construcción morfológica. Así, mientras que un perro de Pekín, por ejemplo, es simplemente un perro que vive en Pekín, vagabundea por sus calles, etc., un perro pequinés es un perro de una terminada especie, «el de raza chinotibetana, de cuatro u ocho kilogramos de peso, colores diversos, patas cortas y cabeza de tipo acondroplásico, que recuerda la de un mastín de nariz aplastada», como define el DRAE; mientras que la combinación gobierno de Madrid pueden entenderse tanto en

${ }^{9}$ El caso del gentilicio español, del provenzal espaignol, procedente, a su vez, del lat. mediev. hispaniolus, constituye una excepción a esta regla. Esta procedencia extraña de la voz ha ofendido hasta tal punto el pundonor nacional, que Lapesa ha tenido que decir que «no debemos considerar desgracia nacional o desdoro el que español sea un provenzalismo. Lo es tan noblemente como homenaje, vergel, deleite, solaz, donaire, doncella, maestre, fraile, monja y tantos más. Aparte de que muchas tierras occitanas fueron feudatarias de soberanos aragoneses, el influjo de la inmigración "franca" fue beneficioso: trajo corrientes europeas que impidieron la total semitización de la España cristiana, donde si hubo arte mozárabe y mudéjar, florecieron también el románico y el gótico. Con el tiempo, el elemento "franco" se incorporó sin residuos a la forma de vida española» (1984: 136). 
el sentido de 'gobierno de España, que se encuentra en Madrid' como en el sentido de 'gobierno de la comunidad autónoma de Madrid', porque la relación es externa, la combinación gobierno madrileño solamente puede entenderse en este segundo sentido, porque la complementación es interna; en Aznar viene de América, el topónimo funciona como simple lugar externo de procedencia'; en Aznar viene americano, el topónimo aparece convertido en rasgo interno (complemento predicativo, dice la gramática tradicional) del sujeto. Es como si dijéramos que viene americanizado: hablando americano, vistiendo a la moda americana, pensando como los americanos, etc. Por eso, parece lógico considerar que los verdaderos gentilicios son los morfológicos, no los sintácticos.

Con las denominaciones gentilicias divide el hombre la tierra en dos mundos distintos: el suyo, al que pertenecen todos aquellos (personas, animales, plantas, paisaje, etc.) que lo comparten, y el de los otros o extranjeros (constituido también por personas, animales, plantas, paisaje, etc.), al que pertenecen todos aquellos que habitan fuera de su mundo, a los que se opone de forma radical. La identidad del hombre se establece aquí por contraste territorial, como, en las lenguas naturales, los fonemas se definen en función del lugar que ocupan en el sistema. Con ello, desaparecen las relaciones de solidaridad, jerarquía y oposición determinadas por las antiguas denominaciones clánicas $^{10}$ y totémicas ${ }^{11}$, y se imponen otras de nuevo cuño. De un lado, las relaciones de solidaridad no se limitan ahora al reducido ámbito de la familia o el clan, sino que se amplían considerablemente a un mundo mucho más complejo, en el que participan gentes de clanes distintos y hasta entes de otras naturalezas, como animales, plantas, paisaje. Digamos que con el gentilicio supera el hombre el diminuto mundo de la tribu y adquiere una perspectiva mucho más amplia: de las relaciones de parentesco, que son relaciones naturales, se pasa a las relaciones de paisanaje, que son relaciones sociales, en que, teóricamente por lo menos, todos tienen el mismo derecho sobre el terreno. Es lo que se refleja en expresiones hechas del tipo Lo que hay en España es de los españoles. De otro lado, las relaciones de jerarquía no se basan en la nueva situación en criterios biológicos o supersticiosos más o menos ancestrales, o en habilidades prácticas personales, sino que se basan en criterios mucho más complejos de correlación de fuerzas o sufragio ${ }^{12}$. El jefe no es ahora un cabecilla con destreza e ingenio ${ }^{13}$

${ }^{10}$ Es lo que ocurre en el caso del antiguo pueblo judío, donde la vida del grupo se organizaba en torno al pater familias, como se comprueba en los libros del Antiguo Testamento. Se trata de una práctica común en todo el mundo semítico.

${ }^{11}$ En el sistema totémico, el origen o propietario de la estirpe es un animal, una planta, un río, etc., como se ve en tantos pueblos antiguos de América, África, Oceanía, etc. En la primera mitad del siglo pasado, estudia Lévi-Strauss en Brasil una aldea que «era en su mayoría del clan mielat ('del jabalí'); pero se había formado por intermatrimonios con otros clanes: Parawat ('del río'), Takuwatip ('del bambú') y algunos otros. Ahora bien, todos los miembros del último clan citado se llamaban con nombres derivados del epónimo: Takwame, Takwarumé, Takwari, Walera (que era un gran bambú), Topehi (fruto de la misma familia) y Karamua (también una planta, pero no indentificada)» (1976: 356). También parece haber sido una constante en los pueblos europeos antiguos, a juzgar por la cantidad de nombres de animal (lobo, oso, caballo, águila, toro, etc.) que perviven en la onomástica personal del continente.

${ }^{12}$ Un ejemplo: cuando la vieja sociedad saharaui se convierte en sedentaria, entran en crisis sus estructuras de parentesco (familia reducida, familia extensa, subfracción, fracción, tribu) y empieza a surgir una división embrionaria en clases sociales, que va penetrando y superponiéndose a la vieja estructura social (Villar, 1982: 169). 
para velar por los intereses y la seguridad de una banda; es un monarca o un presidente, que tiene que contar con el consenso de muchos para gobernar un estado. Lo que quiere decir que el gentilicio es la puerta por donde entra el hombre en la modernidad. Por último, también se alteran radicalmente las relaciones de oposición, puesto que el enemigo del hombre no es ahora algo incierto (banda, animal salvaje, fenómeno natural), que puede surgir de cualquier lugar, y que aquel combate muchas veces con la superstición, sino algo mucho más localizado, que se combate con las armas: abarca a todo aquel que habita en un espacio vital distinto del suyo, y hasta ese mismo espacio vital, que intentará someter. El gentilicio le aclara el panorama al hombre. De ahí los verbos invadir, conquistar, expugnar, asolar, ocupar, saquear, sitiar, colonizar, arrasar, etc. En la nueva era, no se lucha solo para vengar asesinatos o raptos de mujeres, por agravios comparativos o instinto de conservación; se lucha por el territorio, con todo lo que ello implica. De sobra sabido es que muchos de los conflictos del mundo moderno son conflictos de gentilicios ${ }^{14}$. Vistas las cosas así, el territorio deja de ser un hecho puramente objetivo o físico, una referencia topológica sin más, como lo era antiguamente, y se convierte en un hecho casi sagrado, en un sentimiento, en patria o nación ${ }^{15}$, que hay que mantener unida a toda costa ${ }^{16}$, defendiéndola sobre todo de las agresiones de los otros, de los que no son los nuestros ${ }^{17}$. Hablamos, es obvio, del nacimiento del nacionalismo, que tantas consecuencias, buenas y malas, ha tenido, y sigue teniendo, en la vida del ser humano.

Como el gentilicio hace depender la identidad del ser humano, su singularidad frente a los otros, su alma, de la tierra que habita y de lo que ella abarca, este se niega a aceptar cualquier tipo de intromisión extraña en la gestión de su patria. «Nadie que ame inteligentemente lo suyo —escribe el citado Pedro García Cabrera- puede consentir

${ }^{13}$ Por ejemplo, según señala Lévi-Strauss, el jefe nambiquara «debe tener un conocimiento consumado de los territorios frecuentados por su grupo y por los grupos vecinos; visitar asiduamente los terrenos de caza, los bosquecillos de frutales salvajes, saber cuál es el período más favorable de cada uno de ellos; hacerse una idea aproximada de los itinerarios de las bandas vecinas, ya sean amigas o enemigas» (1976: 310).

${ }^{14}$ ¿Qué es el conflicto nacionalista en España sino un enfrentamiento entre los gentilicios español, vasco, catalán, canario, gallego..., o, mejor, un enfrentamiento entre lo que estos gentilicios representan?

${ }^{15}$ En realidad, desde el momento que prende la vida, cualquier trozo de terreno se convierte en una nación o nacimiento, independientemente de que este se encuentre o no ocupado por el hombre, pues también los animales, las plantas y los minerales nacen.

${ }^{16}$ Uno de los factores fundamentales de unidad de la patria es la lengua, que impone un sistema de símbolos iguales para todos. De ahí la obsesión de los nacionalismos por inventar una exclusiva, cuando no la tienen, o de mantenerla unida a ultranza, cuando la tienen.

${ }^{17}$ De sobra sabido es cómo se suele estimular el orgullo patrio, apelando más a los sentimientos, a través de himnos, banderas, contiendas de deportes vernáculos o internacionales (en las que lo que importa no es tanto el juego en sí mismo y por sí mismo, como la rivalidad y el negocio), manifestaciones folklóricas más o menos reaccionarias, mixtificaciones de la historia, celebraciones patrióticas, ocultación de defectos, etc., que a la reflexión, el conocimiento y la ciencia. Esta concepción infame de la patria, en que la gente se afirma negando al otro, ha sido puesta en solfa más de una vez por nuestros intelectuales más destacados. Así, respecto de España, dice Machado: «Los que hablan de España como de una razón social que es preciso a toda costa acreditar y defender en el mercado mundial, esos para quienes el reclamo, el jaleo y la ocultación de vicios son deberes patrióticos, podrán merecer, yo lo concedo, el título de buenos patriotas; de ningún modo el de buenos españoles» (1972: 96). El nacionalismo sectario es una la religión, no un ente de razón, como hace ver Tortosa (1996). 
una transferencia de alma» (2005: 26). Es decir, que esas palabras que llamamos gentilicios constituyen la raíz y el arranque del ansia que manifiestan los pueblos del mundo - sin distinción de tamaños - a la libertad y la independencia. En cuanto toman conciencia de la singularidad más o menos acusada que todos poseen, los pueblos del mundo, sean grandes o pequeños, insistimos, aspiran a convertirse en estados, para desarrollar plenamente todas sus posibilidades como pueblo. El sentimiento de que el otro se entromete en los asuntos de la patria o intenta aprovecharse de ella conduce habitualmente a expresiones calificativas injuriosas, como el godo con que se designa despectivamente en Canarias y América al español peninsular, o el maqueto con que se designa en el país vasco a los españoles que no proceden de esa comunidad autónoma.

¿En qué momento de la historia acaece este cambio ${ }^{18}$ tan trascendente en la definición del hombre? Al parecer, el cambio se produce cuando el hombre abandona el sistema de vida de horda y nomadismo que había practicado en el principio de los tiempos, y se asienta de forma más o menos definitiva en un territorio, donde labra el suelo que le proporciona el alimento que lo sustenta (nacimiento de la agricultura), construye la morada que lo protege de los rigores ambientales y cava la tumba en que reposará eternamente, convirtiéndolo así en su propiedad privada más preciada. «La posesión por parte de la estirpe de suelo - escribe Wundt- consolida un nuevo estado, dentro del cual va apareciendo cada vez más la propiedad privada» (1990: 110).

Es evidente, por tanto, que, al definir al hombre en función de la nación, y no en función de la tribu, el gentilicio amplía considerablemente las posibilidades de aquel. ¿Se trata de una etapa de la historia de la humanidad superable? Aunque la globalización hizo pensar en principio que sí, que era posible eliminar las fronteras nacionales, y construir una patria humana para todos, el posterior resurgir de las reivindicaciones nacionalistas ha hecho replantearse el problema. ¿Por qué este reavivamiento nacional? Pues por la tendencia del hombre a singularizarse frente a los demás, a mantener su propia identidad a toda costa: el hombre sabe que la uniformidad total acaba con la libertad, que cuanto más sociedad, menos individuo. Por eso se apega tanto a sus singularidades territoriales, que son las que le permiten ser él mismo; él, y no el otro.

Como es natural, la peculiaridad semántica que comentamos, el hecho de que los gentilicios sean adjetivos derivados de nombres propios de lugar, determina de forma radical su funcionamiento en la realidad concreta del hablar.

En primer lugar, determina que puedan usarse, y de hecho se usen, para designar, no solo a las personas nacidas en el territorio aludido, sino también a los animales criados en él, a las plantas que produce, a los minerales que yacen en su subsuelo, a los fenómenos atmosféricos que lo caracterizan, etc. Esto quiere decir que la densidad conceptual del gentilicio está determinada, en primer lugar, por las propiedades que el hablante haya seleccionado de la mayor o menor riqueza material e inmaterial del referente del topónimo ${ }^{19}$. Además de estas nociones primarias, como las personas, los ani-

${ }^{18}$ El cambio se encuentra totalmente consolidado en el mundo griego y en el mundo romano, cuyos gentilicios derivan de topónimos, en buena medida.

${ }^{19}$ Un ejemplo sobresaliente de la riqueza natural, cultural, histórica, sentimental, etc., que puede implicar un territorio nos lo proporciona la descripción que de España hace Alfonso X el Sabio en su 
males y las cosas designados por ellas poseen, a su vez, formas de expresarse, atributos, comportamientos, etc., específicos, el gentilicio desarrolla también acepciones secundarias, referidas al aspecto, el comportamiento, los hábitos gastronómicos, la vestimenta, la forma de hablar, las aspiraciones, la ideología, la historia, la economía, etc., propios de las personas (principalmente de las personas, por tratarse del referente primario más importante del gentilicio), los animales, los minerales, los fenómenos naturales, etc., aludidos ${ }^{20}$. Muchos de estos sentidos secundarios son de desarrollo local, por lo que, para detectarlos, hay que acudir a los glosarios dialectales correspondientes. Un ejemplo muy claro de lo que decimos nos lo proporcionan las acepciones 'persona que en una operación de compraventa siempre saca ventaja', 'persona mezquina, tacaña' y 'borracho' que ha desarrollado el gentilicio turco en determinados países de Hispanoamérica ${ }^{21}$.

En todo caso, hay que tener en cuenta que buena parte de estas propiedades, más que reales, son atribuidas, bien por los otros, por personas ajenas al grupo designado, bien por los mismos implicados en la denominación, vivan dentro o fuera del país, que son dos formas distintas de hacer patria. Los que viven dentro la hacen disfrutándola o sufriéndola realmente cada día. Los que viven fuera, idealizándola a través del sentimiento de la añoranza, nostalgia o magua que provoca la lejanía y el contraste con otros pueblos ${ }^{22}$, apreciándola así mejor. Siempre se ha dicho que, para curarse del nacionalismo, hay que viajar. Yo no sé si el viajar cura o no del nacionalismo; lo que sí sé es que nos permite conocer a los otros y, consecuentemente, a que nosotros mismos nos conozcamos mejor. En todo caso, es evidente que no es lo mismo el concepto que tiene de la patria el paisano que no ha salido nunca de casa que el concepto que tiene el emigrante. Es claro, pues, que la patria, más que una realidad material, es una cons-

Crónica general: «Espanna es abondada de mieses, deleytosa de fructos, viciosa de pescados, sabrosa de leche y de todas las cosas que se della fazen. Llena de uenados e de caça, cubierta de ganados, loçana de cauallos, provechosa de mulos, segura et bastida de castiellos, alegre por buenos uinos, ffolgada de abondamiento de pan; rica de metales, de plomo, de estanno, de argent uiuo, de fierro, de arambre, de plata, de oro, de piedras preciosas, de toda manera de piedra mármol, de sales de mar et de salinas de tierra, et de sal en pennas, et dotros mineros muchos; azul, almagra, greda, alumbre et otros muchos de quantos se fallan en otras tierras; briosa de sirgo, et de quanto se faze dél, dulçe de miel et de açúcar, alumbrada de cera, complida de olio, alegre de azafrán. Espanna sobre todo es engennosa, atreuuda et mucho esforzada en lid, ligera de affán, leal al sennor, afficada en estudio, palaciana en palabra, complida de todo bien; non a tierra en el mundo que la semeie en abondança nin se eguale ninguna a ella en fortalezas, et pocas a en el mundo tan grandes como ella. Espanna sobre todas es adelantada en grandez, et más que todas preciadas por lealtad. ¡Ay, Espanna! Non a lengua nin engenno que pueda contar tu bien» (apud Cela, 1988: 11).

${ }^{20}$ Para todo lo relacionado con la naturaleza semántica de esta información del gentilicio, vid. Morera y García Padrón (en prensa).

${ }^{21}$ Véase Morales Pettorino y Quiroz Mejías (1987: s. v.).

${ }^{22}$ Aunque lo normal es amar a la patria, no faltan casos de rechazo, y hasta de apostasía. Es lo que pone de manifiesto la expresión hecha española Si habla mal de España es español. No sé de nadie que escribiera palabras más terribles sobre sus paisanos que Nietszche: «Y cuando ni siquiera se es limpio, ¿cómo se va a tener profundidad? [...] en el alemán no se llega nunca al fondo, sencillamente porque no lo tiene: eso es todo. Lo cual no quiere decir que sea superficial. Lo que en Alemania se considera "profundo" es precisamente esa suciedad instintiva para con uno mismo a la que me acabo de referir: no se quieren tener las cosas claras respecto a uno mismo. ¿Podría proponer que se usara internacionalmente la palabra "alemán” para designar esa depravación psicológica» (1988: 154). 
trucción ideológica, una leyenda, en la que no solamente participan sus titulares; participan además, y en muy buena medida, los rivales de estos, los que habitan fuera del ámbito territorial que los define ${ }^{23}$. En la forja de este mito no juega un papel menor la ficción artística, principalmente la literaria, que crea la conciencia de su flora, su fauna, su historia, sus lugares, etc., al fijar sus nombres por escrito ${ }^{24}$, mitifica las acciones de sus gentes, inventa su paisaje y desarrolla las posibilidades de la lengua con que se imponen los símbolos colectivos. ¿Quién ha contribuido más a la creación de esa patria que se llama España, los españoles y lo español que su riquísima tradición literaria, desde El Cid hasta el último de nuestros escritores contemporáneos, pasando por San Juan de la Cruz, Santa Teresa, Cervantes, Quevedo, Unamuno o Juan Ramón Jiménez? ¿Quién ha trabajado más por la creación de esa patria que se llama Argentina, los argentinos y lo argentino que su importantísima tradición literaria, que va desde Hidalgo, Echeverria, Alberdi o Sarmiento hasta Sábato, pasando por José Hernández, Güiraldes, Cortázar o Borges? Con razón dice T. S. Eliot, siguiendo a Ch. Eliot Norton, que «el pueblo que descuida su patrimonio literario deviene bárbaro; el pueblo que deja de producir literatura paraliza su pensamiento y su sensibilidad. La poesía de un pueblo toma vida del habla y a su vez le da vida: representa su expresión más acabada de conciencia, poder y sensibilidad» (1968: 25).

El gentilicio actúa, pues, como una especie de archivo que contiene todos los datos de la gente, los animales, las plantas, los fenómenos naturales, etc., del lugar a que se refiere, y de todas las cosas pertenecientes o relativas a ellos, reales o atribuidas, insistimos. Hasta tal punto es así, que se puede decir que el gentilicio es la palabra que mejor define al hombre como miembro de una colectividad ${ }^{25}$. Es lo que explica la sensación de carencia o manquedad que se siente cuando un determinado pueblo, por las razones que $\operatorname{sean}^{26}$, no ha actualizado el gentilicio que le corresponde. Por ello, si que-

${ }^{23}$ Recuérdese, por ejemplo, la importancia que ha tenido la llamada «leyenda negra», inventa$\mathrm{da}$, al parecer, por los ingleses (rivales de España en la conquista y colonización de América), en la definición de España, los españoles y lo español; o la trascendencia de los árabes, rivales de los cristianos en la península ibérica durante más de 800 años, en la formación, no solamente del vocabulario español, sino también de nuestra personalidad más profunda, como nos ha hecho ver Américo Castro (2001). Desde el momento mismo de la conquista, los naturales de cada una de las islas canarias fueron víctimas de la valoración no precisamente compasiva de sus paisanos de las otras. Así, según señala Torriani, «los lanzaroteños son considerados asesinos; los de Fuerteventura, indolentes; los canarios, mentirosos; los de Tenerife, ingratos; los gomeros, traidores; los de El Hierro, toscos; y los palmeros, vanidosos» (1978: 14).

${ }^{24} \mathrm{La}$ escritura es un poderoso factor de unión: «La lucha contra el analfabetismo se confunde con el fortalecimiento del control de los ciudadanos por el Poder. Pues es necesario que todos sepan leer para que este último pueda decir: nadie está reputado como ignorante de la ley» (Lévi Strauss, 1976: 297).

${ }^{25} \mathrm{La}$ fuerza identificadora de los gentilicios es tal, que muchos de ellos se usan como apellidos de las personas. Vid. García Gallarín (2001).

${ }^{26}$ Esas causas pueden ser muy diversas. La más frecuente es la mayor o menor importancia que se dé a la pertenencia al territorio. A pesar de las formas gentilicias que recoge Casares para Fuerteventura en su Diccionario ideológico (olivense (olivero) 'natural de La Oliva', tetireño 'natural de Tetir', pajareño 'natural de Pájara', tuinejero 'natural de Tuineje'), que son de uso muy esporádico, o, simplemente, artificiales, los habitantes de este territorio canario se definen siempre en función de la isla (majoreros), no en función del pueblo de la isla en que moran. De ahí que estos carezcan, por lo general, de gentilicio propio. Digamos que lo que define aquí al hombre es la entidad isla, no la entidad pueblo concreto de esta. Es como si los majoreros nunca hubieran sentido la necesidad interna de diferenciarse unos de otros. Otra cosa son 
remos dar cuenta de la riquísima información semántica que, por lo general, envuelve el gentilicio, no basta con definirlo como 'perteneciente o relativo a' o 'natural de', como suelen hacer los diccionarios al uso, sino que habría que definirlos de forma enciclopédica. Así, en la definición del gentilicio francés, no bastaría con decir que esta palabra significa 'perteneciente o relativo a Francia' y 'natural de Francia ${ }^{27}$, sino que habría que entrar en los aspectos más relevantes del físico, el carácter, la historia, la sociedad, etc., de la gente aludida. Cuando nos limitamos a decir que francés significa 'perteneciente o relativo a Francia' y 'natural de Francia', lo que hacemos realmente es eludir la problemática responsabilidad ${ }^{28}$ de definir la palabra en términos concretos, haciendo recaer sobre el lector el compromiso de deducir lo que haya que deducir de la información enciclopédica que implica el topónimo Francia ${ }^{29}$.

Con frecuencia, estos sentidos secundarios adquieren tanta estabilidad en la norma lingüística, que terminan convirtiéndose en acepciones independientes de la acepción básica de que derivan. Por ejemplo, los sentidos 'falto de entendimiento o razón'30 y 'tartamudo' que, por razones culturales diversas, ha desarrollado el gentilicio gallego

las variadas denominaciones externas con que se motejan los unos a los otros, que, como tales denominaciones externas, obedecen a razones apelativas, no a razones de definición territorial.

${ }^{27}$ En este sentido, resultaba mucho más profundo Covarrubias, que, después de definir a los francos como 'naturales de Francia', añadía que «los autores antiguos los han tenido por belicosos e ingeniosos en todas las artes, assí mecánicas como liberales. En nuestro tiempo son sumamente orgullosos e inquietos, de manera que anda un refrán que dice: 'Quando el francés duerme, el diablo le mece'» (1611 [1993]: s. v.). Si queremos saber lo que implica realmente un determinado gentilicio, debemos acudir a la bibliografía específica sobre el tema, si la hay, a las opiniones de los filósofos, de los sociólogos o de la gente, en general. Veamos, por ejemplo, de qué manera sutil define Machado a los españoles: «El español suele ser un buen hombre, generalmente inclinado a la piedad. Las prácticas crueles - a pesar de nuestra afición a los toros- no tendrán nunca buena opinión en España. En cambio nos falta respeto, simpatía, y, sobre todo, complacencia en el éxito ajeno. Si veis que un torero ejecuta en el ruedo una faena impecable y que la plaza entera bate palmas estrepitosamente, aguardad un poco. Cuando el silencio se haya restablecido, veréis, indefectiblemente, un hombre que se levanta, se lleva los dedos a la boca, y silba con toda la fuerza de sus pulmones. No creáis que ese hombre silba al torero — probablemente él lo aplaudió también-: silba al aplauso» (Machado, 1976: 95).

${ }^{28} \mathrm{Y}$ digo «problemática responsabilidad», porque el analista tiene que dar cuenta hasta de las valoraciones más o menos despiadadas (y casi siempre son despiadadas, porque los otros no nos ven nunca, o casi nunca, con buenos ojos) que los demás hacen de la gente aludida por el gentilicio. En la descripción rigurosa del gentilicio, tropieza el analista con problemas éticos de gran envergadura. Estos escrúpulos morales ha llevado recientemente a la Real Academia a eliminar la acepción 'tonto' del artículo gallego. Se trata, indudablemente, de una postura absolutamente respetable. Lo esperable ahora es que se sea coherente con el principio y se haga lo mismo en el caso de todos aquellos otros gentilicios que poseen acepciones similares. Por ejemplo, habría que eliminar también la acepción 'que estafa u obra con engaño' del gentilicio gitano. Hay tradiciones lexicográficas que han optado por la solución contraria. La portuguesa, por ejemplo, recoge de forma moderada las acepciones valorativas. Así, según Almeida Costa y Sampaio e Melo, el gentilicio francés, además de las consabidas acepciones gentilicias, presenta la acepciones calificativas 'delicado, mas falso' y 'fingido'; el gentilicio portugués, además de las consabidas acepciones gentilicias, las acepciones calificativas 'franco, a pesar de rudo' y 'leal' (1990: s. v.).

${ }^{29}$ Sugerencias para los problemas generales del tratamiento lexicográfico de los gentilicios pueden verse en Pérez Vigaray (2011). Para lo relacionado con el tratamiento lexicográfico de su información semántica, vid. García Padrón y Morera (en prensa).

${ }^{30}$ Salvo que indiquemos lo contrario, la información lexicográfica que manejamos en este trabajo procede del DRAE-2001. 
en Hispanoamérica; o el sentido de 'bodeguero' con que, según Fernando Ortiz (1985: s. v.), se usa el gentilicio catalán en la provincia cubana de Oriente. Además, a partir de estos sentidos, los gentilicios pueden usarse para designar, por aplicación metafórica, gentes de pueblo o lugares distintos del originario. Es, por ejemplo, el caso del polaco que emplean los castellanos para designar a los catalanes, al parecer, porque estiman la lengua de estos tan incomprensible para ellos como la propia de los polacos; o el del catalán que se emplea en Toledo para designar a los naturales de Castillo de Bayuela, por su fama de tacaños, cualidad que se atribuye a la gente de Cataluña. Cuando designamos a un pueblo mediante el gentilicio de otro, lo que hacemos es encerrarlo en su misma órbita espacial, significarlo de la misma manera, hacerlo de esa tierra, aunque esta igualación sea solo momentánea, como, por lo demás, ocurre con toda metáfora.

En segundo lugar, el hecho de que los gentilicios se refieran principalmente a las personas (de ahí precisamente el nombre con que se les denomina) determina que se carguen de connotaciones (generalmente peyorativas) procedentes de la valoración que de ellas hacen los otros grupos humanos (sobre todo los más próximos), en función del comportamiento, la condición, la raza, la capacidad económica, la religión, etc., que aquellas posean o estos les atribuyan ${ }^{31}$. Se trata de connotaciones que afloran frecuentemente aquí y allí en el discurso repetido. De un lado, en expresiones hechas, coplillas populares, etc., como Engañar a alguien como a un chino 'aprovecharse de su credulidad', cabrearse como un chino 'enfadarse mucho'; Tener alguien un chino atrás 'tener mala suerte' (Cuba); Todo español es abogado, mientras no se demuestre lo contrario; Son españoles los que no pueden ser otra cosa; Al andaluz, hazle la cruz; Majorero y burro negro, de ciento sale uno bueno; Un majorero fue a misa/ y no sabía rezar, y lo primero que dijo:/ 'Tesia, camello, p'atrás ${ }^{32}$; etc. De otro lado, en chistes étnicos más o menos ingeniosos, que, desde el punto de vista valorativo, pueden clasificarse en dos categorías muy distintas: Chistes étnicos de insulto, que son generalmente creados por personas ajenas al titular del gentilicio. Por ejemplo: los chistes de judíos, en toda Europa, tan bien analizados por Freud en su El chiste y su relación con el inconsciente, los de leperos, en España, y los de gomeros, en las islas canarias; y chistes étnicos de exaltación, generalmente salidos de la inventiva de los titulares del gentilicio, donde estos se retratan ganándole siempre la partida al resto de la humanidad. Recuérdense al respecto los tantos chistes del repertorio nacional donde ingleses, franceses, alemanes, italianos, americanos, etc., salen siempre malparados en sus porfías o disputas dialécticas o no con los españoles. Estas valoraciones que comentamos suelen ser más o menos circunstanciales, lo que dificulta enormemente su descripción. En todo caso, condicionan de forma radical tanto el uso como la evolución de las palabras que nos ocupan. Así, en sus Ordenanzas Reales de 1768, Carlos III prohíbe portar la bandera a

${ }^{31}$ Sobre la naturaleza semántica de este tipo de connotaciones valorativas y su tratamiento lexicográfico, vid. Herrera Santana (2012).

${ }^{32}$ Navarro Artiles (s. f.). En muchos casos, lo implicado en la expresión hecha no es el gentilicio, sino el topónimo de base, como se observa en frases del tipo De Aragón, ni hembra ni varón; De La Palma y La Gomera, nunca viene cosa buena; De Navarra, ni mujer ni tronada. 
«murcianos y gente de mal vivir», por la mala fama que tenían entonces los naturales de Murcia $^{33}$.

$\mathrm{Y}$, como la información denotativa y connotativa que contienen los gentilicios es múltiple y abierta, la definición cultural e ideológica de estos tiene que ser necesariamente problemática. ¿Qué define propiamente lo español? $\mathrm{O}$, dicho de forma más precisa, ¿qué, de lo perteneciente o relativo a España, define propiamente lo español? Desde el punto de vista puramente toponímico, la pregunta tiene fácil respuesta: español es todo aquello que pertenece o se relaciona con España, independientemente de la condición de la persona, animal o cosa de que se trate. En este sentido tendríamos que tan español como lo castellano o andaluz es lo catalán, lo vasco, lo gallego o lo canario, porque todo ello se encuentra dentro de esa entidad jurídica que se llama España. Vistas las cosas así, se puede decir que a los castellanos o a los canarios, por ejemplo, no los define solamente lo castellano o lo canario, sino también lo andaluz, lo catalán, lo vasco, lo gallego, etc., que, como españoles, han jugado un papel decisivo en la forja de la cultura que todos compartimos. Pero frente a esta forma amplia de ver las cosas, están, como es de sobra sabido, los mercachifles y los políticos indocumentados o sin escrúpulos, que, con exclusión de todo lo demás, reducen lo español a unos cuantos aspectos de España, frecuentemente el flamenco, los toros, la tortilla de papas, el jamón serrano, el botijo y el habla de Castilla, para venderla y mangonearla mejor (de marca España se habla hoy). Desde este mezquino punto de vista, no serían españoles la lengua catalana, la lengua vasca, el habla andaluza, la butifarra, el vino chacolí, el pulpo a la gallega, las papas arrugadas, la sardana, la jota aragonesa o la polka majorera. Esta usurpación del nombre español por unos cuantos símbolos identitarios más o menos caricaturescos, que se defienden en muchas ocasiones mediante instituciones oficiales creadas para arrancar las plantas nativas que no interesan, no solamente tergiversa la realidad de la patria, sino que, además, suele llevar a desafecciones más o menos graves de lo nacional, como ha demostrado suficientemente la historia. ¿Por qué repugna a muchos aceptar que la lengua vasca, la lengua catalana y el gallego son tan españoles como el castellano? ¿Por qué han tenido (y, en muchos casos, siguen teniendo, a pesar de todo lo que se ha avanzado en el reconocimiento de la diversidad lingüística y cultural en los últimos tiempos) tantos problemas de legitimidad el andaluz, el canario, el extremeño, el cubano, el peruano, etc., siendo, como son, desarrollos tan legítimos de la lengua española como el habla de Castilla y siendo, como es, que dicha lengua solamente está completa en su diversidad? ${ }^{34}$ Pues simplemente porque la lengua de Castilla (mejor, la particular modalidad lingüística de Castilla) usurpa el nombre de todos ${ }^{35}$. Se

${ }^{33}$ Para algunos, este murciano no deriva del topónimo Murcia, sino del nombre de germanía murcio (de murciégalo) 'ladrón o ratero'. Morfológicamente, se trata de una hipótesis poco verosímil.

${ }^{34}$ En relación con Canarias, he tratado este asunto en Morera (2005, 2006 y 2007a y b).

${ }^{35}$ Un análisis exhaustivo de los problemas que plantea el nombre de la lengua española puede verse en el clásico trabajo de Amado Alonso (1942). La práctica de definir la lengua en función del nombre de la nación tiene, como es de sobra sabido, sus pros y sus contras. Por una parte, parece inevitable que la lengua se defina en función del nombre de la patria, porque, en cierta manera, lengua y patria van inextricablemente unidas. Las palabras de aquella contienen todo lo que esta es y todo lo que esta ha hecho a lo largo de la historia. De ahí que no sea ninguna exageración decir que, cuando el hombre se expresa, habla o canta, se expresa, habla o canta la tierra. La lengua es uno de los indicios más claros de la pertenencia o no de un 
sabe, porque lo han dicho ya muchos conocedores del asunto, que buena parte de los conflictos lingüísticos de España se acabarían aceptando la realidad tal y como es: que el vasco, el catalán y el gallego son tan lenguas españolas o nacionales como el castellano, y que el español de Argentino, el español de Cuba, el español de Nicaragua, el español de Canarias, el español de México, etc., tan buen español como el español de Castilla.

La misma complejidad semántica del gentilicio hace también enormemente difícil la definición histórica de la nacionalidad. Pensemos, por ejemplo, en lo que ha sucedido en el caso del citado español. Para algunos historiadores, la forja de la personalidad española se retrotrae a la Hispania latina, o antes.

Nos sentimos inclinados a pensar que Séneca, asimilándose tendencias ya existentes en Roma, realiza por primera vez un tipo de expresión lingüística española, rebelde por exuberancia a las normas de escuela; rompe la mesura ciceroniana en busca del brillo, la agudeza y «el concepto», y su rebuscada independencia que le lleva al barroquismo es precisamente la que le hace siempre sugestivo y nuevo entre los antiguos. Del sobrino de Séneca, Lucano, se ha dicho repetidas veces que muestra un cordobesismo en la pompa, en la hipérbole y en la truculencia; en la ingeniosidad, exceso y oscuridad de metáforas. Más tarde, Marcial, que siente reiteradas veces la necesidad de gritar ante Roma su hirsuto celtiberismo, lleva también algo del realismo hispano (Menéndez Pidal, 2005: 108-109).

Sánchez Albornoz (1957) piensa, por el contrario, que la personalidad española se forja fundamentalmente a partir de la arribada de los pueblos germánicos a la península ibérica. Para Américo Castro, esta empieza a germinar verdaderamente a partir de la edad media, en la empresa de la Reconquista, con todo lo que ello implicaba: «La religión española como su lengua, sus instituciones, su escasa capacidad para la ciencia objetiva, su desborde expresivo y su personalismo integral ha de ser referida a los 900 años de entrelace cristiano-islámico» (2001: 97). Otros retrasan el origen de lo español mucho más acá, a la unificación política de los distintos reinos peninsulares llevada a cabo por los Reyes Católicos, o al reaccionario dogmatismo religioso de Trento. Para Unamuno, por ejemplo, una de las características de la personalidad del español es llevar dentro un inquisidor. Desde el punto de vista de la lengua, lo único que podemos decir es que de nacionalidad española solamente se puede hablar a partir del nacimiento del gentilicio español, que, según Rafael Lapesa, debió de designar en principio a «los hispano-godos refugiados en el Mediodía francés al sobrevenir la invasión musulmana, y luego a sus descendientes» (1984: 134).

individuo a la tierra. Si no se habla la lengua o la modalidad lingüística de un lugar, muy difícilmente puede uno definirse como natural de ese lugar. Por otra parte, es injusto definir la lengua en función de la patria por dos razones distintas. En primer lugar, porque, en los casos en que se convierte también en vehículos de expresión de otros países, hiere el orgullo de sus gentes, al hacerles sentir que hablan la lengua de quienes los colonizaron. En segunda lugar, porque, cuando el país que la posee tiene más lenguas, monopoliza injustamente la representación de la nacionalidad, silenciando o anulando el resto de sus manifestaciones expresivas. 
Por lo mismo, también resulta enormemente problemática o conflictiva la aplicación del gentilicio en la realidad concreta del hablar. ¿A quiénes de la gente relacionada con una tierra determinada se puede aplicar inequívocamente el gentilicio que corresponde a aquella? Por ejemplo, ¿quiénes de la gente que vive en España son realmente españoles? Esta pregunta, tan frecuente en los tiempos de migraciones y mestizajes que nos ha tocado vivir, ha recibido respuestas muy diversas (algunas racistas), dependiendo del punto de vista que se haya adoptado. Por una parte, están los que, desde el punto de vista biológico o de la sangre, piensan que genuinamente españoles solo son aquellas personas que han nacido de padres españoles y se han criado dentro de la tradición cultural de España. Por otra, están los que, desde el punto de vista meramente ciudadano, opinan que, independientemente de su procedencia geográfica, raza, parentesco, cultura, religión, etc., español es toda aquella persona que forma parte de su sociedad. En tercer lugar, están las leyes, que nos dicen que son españoles todos aquellos que tienen nacionalidad española. En cuarto lugar, tenemos a los que, desde el punto de vista histórico, consideran que genuinamente españoles solamente son los cántabros, los astures, los castellanos, etc., que fueron los creadores de la raza, no los añadidos posteriores. En quinto lugar, por último, están los que, desde el punto de vista sentimental, consideran que español es en realidad todo aquel que se siente como tal, al margen de que haya nacido o no en España y de que viva o no dentro del territorio nacional. A pesar de que se trata de opiniones encontradas, todas ellas caben dentro de la significación del adjetivo de relación español, que lo único que significa constante e invariablemente es algo así como 'que presenta internamente el concepto España'. Es decir, lo único que exige el adjetivo español al referente del sustantivo que lo rige es que 'guarde algún tipo de relación con España', pero no un tipo de relación determinada. ¿Quién tiene, pues, razón en esta disputa desde el punto de vista extralingüístico? Pues todos tienen razón desde su particular perspectiva. Si hubiera que valorarlas, acaso habría que decir que la última es la más justa de todas ellas, porque hace depender la españolidad del sentimiento o la querencia, no de la obligación. Con este criterio en mano, sería español el que se sienta como tal, o quiera serlo. La más injusta, y hasta siniestra: aquella que hace depender la nacionalidad de la sangre o la raza ${ }^{36}$. Todo esto pone de manifiesto el poder que tienen las palabras, cómo la organización (siempre arbitraria) que confiere la palabra a la realidad condiciona de tal manera la vida del hombre y su comportamiento, que este hasta es capaz de matar por ese mito.

Otro ejemplo más o menos claro. Como tantos otros lugares del planeta, en las últimas décadas, el desarrollo turístico ha convertido a la isla de Fuerteventura en foco de atracción de las gentes de las más variadas procedencias (canarios, andaluces, gallegos, alemanes, ingleses, italianos, marroquíes, colombianos, ecuatorianos, argentinos, cuba-

${ }^{36}$ Por no hablar de otros casos tan sangrantes como este, la peligrosa paranoia indigenista ha llevado a clasificar la población canaria en tres clases perfectamente diferenciadas, que un panfleto político define en los siguientes términos: guanches de nacimiento, 'los nacidos de padres canarios y comprometidos en la lucha por la liberación de su patria guanche'; guanches de absorción, 'los nacidos en la tierra sagrada de la patria canaria, pero de progenitores extranjeros'; y guanches de integración o espirituales, 'los extranjeros que defienden de forma indubitable la independencia de la patria canaria'. Respecto de las peligrosas consecuencias de estos planteamientos racistas, vid. Morera (2007d). 
nos...), que han echado raíces y se han heredado en ella. ¿Puede decirse que se trata de majoreros? Desde el punto de vista de la ciudadanía, no cabe la menor duda de que lo son. Sin embargo, hay majoreros de los de antes que se resisten a aceptarlo. Admiten de más o menos buen grado que, efectivamente, estas personas sean de Fuerteventura, pero niegan categóricamente que sean majoreros ${ }^{37}$.

En tercer lugar, la capacidad del ser humano para colonizar lugares distintos de aquel que lo vio nacer y que, por lo general, le da nombre, así como el hecho de que a lo largo de la historia un mismo lugar pueda ser ocupado por gentes de distintas procedencias, determinan que muchos gentilicios amplíen, tanto territorial como temporalmente, su radio de acción originario. Así, el citado gentilicio gallego, que originariamente solo significaba 'perteneciente o relativo a Galicia', ha pasado a significar en América 'perteneciente o relativo a España', precisamente porque buena parte de la emigración española a las distintas repúblicas hispanoamericanas procedía de la mencionada región ibérica; el gentilicio romano, que significaba originariamente 'perteneciente o relativo a la antigua Roma', con el transcurrir del tiempo pasó a significar también 'perteneciente o relativo a la moderna Roma, capital de Italia'; el gentilicio canario, que solo significaba en origen 'perteneciente o relativo a Canarias', ha pasado a significar también 'perteneciente o relativo a Canelones, ciudad y departamento de Uruguay', porque buena parte de la gente que fundó esta ciudad procedía de Canarias; el gentilicio turco, que solo significaba en origen 'perteneciente o relativo a Turquía', ha pasado a entenderse en la América hispana también en los sentidos de 'sirio', 'siriolibanés' y hasta 'árabe, en general', precisamente porque la mayor parte de los emigrantes del mundo árabe en América son turcos ${ }^{38}$. Consecuentemente, Galicia, Roma, Canarias y Turquía no se limitan al territorio de la comunidad autónoma gallega, la Roma antigua, la comunidad autónoma canaria y la Turquía euroasiática, respectivamente. Abarcan también toda la península ibérica, la actual Roma, parte del Uruguay, Siria, Líbano y hasta todo el mundo árabe, pues, a través de sus emigrantes, han transplantado a estos lugares las costumbres heredadas de su patria, que viajaron con ellos como su propia sombra. Es decir, que gallegos, romanos, canarios y turcos galleguizaron, romanizaron, canarizaron y turquizaron España, la Roma moderna, el Canelones uruguayo, Siria, Líbano y el mundo árabe ${ }^{39}$. El emigrante, colonizador pacífico, ensan-

${ }^{37}$ No les falta razón a aquellos que piensan que todo esto de la definición de la patria y el paisanaje es puro aldeanismo; que todos los hombres pertenecemos a la misma patria, a la patria humana o «aldea global», como dicen algunos, y que la solidaridad no debe limitarse a la gente del pago, sino que debe extenderse a todos los seres humanos. Se trata, obviamente, de una bella utopía, pero, de momento, las nacionalidades son una realidad jurídica, política, social, etc., ineludible. Y, como esto es así, creo que lo que hay que hacer es exigir que se gestionen con decencia, respetando escrupulosamente los derechos humanos.

${ }^{38}$ Los aspectos más relevantes del problema de la ampliación del ámbito referencial de los gentilicios pueden verse en Morera (en prensa).

${ }^{39} \mathrm{Y}$ esto independientemente del sentir de las personas aludidas, que no siempre ven estas denominaciones con simpatía. Concretamente, los sirios y libaneses que designan los hispanoamericanos con el gentilicio turco suelen protestar airadamente contra tal denominación, según señala Santamaría (1983, s. v.). 
cha los límites de su viejo solar al transplantar a otros los aires lingüísticos, culturales, gastronómicos, laborales, etc., del suyo ${ }^{40}$.

Aunque, en principio, los diversos valores mencionados (tanto los de naturaleza denotativa como los de naturaleza connotativa) actúan como meros sentidos secundarios superpuestos a la significación básica de 'perteneciente o relativo a' del gentilicio, que es lo verdaderamente dado por la palabra en sí misma y por sí misma, con el tiempo, dichos sentidos pueden terminar lexicalizándose e independizándose completamente de la significación mostrativo-espacial que le sirvió de base ${ }^{41}$. Dicho de otra forma: que el gentilicio puede deponer la significación mostrativa o identificadora que lo caracteriza, y elevar a categoría de valor fundamental alguno de sus sentidos conceptuales concomitantes, transformándose así en signo léxico independiente. Ese ha sido el caso de las formas judio, siamés y campechano, por ejemplo, cuyos sentidos respectivos 'usurero', 'dicho de un hermano, gemelo que nace unido por alguna parte de su cuerpo' y 'que se comporta con llaneza y cordialidad sin imponer distancia en el trato', originariamente concomitante con su valor gentilicio, han perdido ya todo vínculo con las acepciones mostrativas 'perteneciente o relativo a Judea', perteneciente o relativo a Siam, antiguo nombre de Tailandia' y 'perteneciente o relativo a Campeche', respectivamente, y se sienten como unidades léxicas independientes. En este caso, hay que hablar de dos signos distintos (casi homónimos, podríamos decir) sin ninguna relación semánticosincrónica entre sí: uno mostrativo (judio 'perteneciente o relativo a Judea', siamés 'perteneciente o relativo a Siam' y campechano 'perteneciente o relativo a Campeche') y otro descriptivo: judio 'usurero', siamés 'dicho de un hermano, gemelo que nace unido por alguna parte de su cuerpo' y campechano 'que se comporta con llaneza y cordialidad sin imponer distancia en el trato'. Se trata de signos tan alejados de su valor mostrativo originario, que hasta el significante evoluciona en muchos casos a su aire, desarrollando forma propia, distinta de la correspondiente a su étimo. Ejemplo de ello lo tenemos en las formas gálico 'perteneciente o relativo a Francia' y egiptano 'perteneciente o relativo a Egipto', que adquirieron las formas particulares galgo y gitano cuando independizaron de su valor gentilicio originario los contenidos léxicos concomitantes de 'casta de perro muy ligero, con la cabeza pequeña, los ojos grandes, el hocico puntiagudo, las orejas delgadas y colgantes, el cuerpo delgado y el cuello, la cola y las patas largas' y 'se dice de los individuos de un pueblo originario de la India,

${ }^{40}$ Frente al emigrante, está el colono más o menos violento, que arrebata a sus legítimos propietarios las tierras que invade, acabando, casi siempre, con el complejo mundo de sentidos lingüísticos, culturales y religiosos que, con el esfuerzo continuado de siglos o milenios, estos edificaron sobre ella. Recuérdense, por ejemplo, los destrozos humanos, lingüísticos, culturales, etc., que supusieron la romanización de la península ibérica, la britanización de Australia, la portugalización de Brasil o la hispanización de Canarias y América. Claro está que, además del colonialismo presencial, está el colonialismo a distancia, más sutil, perverso y devastador que aquel, porque tiene más alcance, que es el que practican los imperios modernos. Es, como es de sobra sabido, el que ejerce los Estados Unidos de América sobre el resto del planeta, a través de su cine hegemónico, sus canales de televisión internacionales (Disney Channel, por ejemplo, verdadero peligro público para la formación espiritual de los niños del mundo), su pseudociencia de supermercado, la obscena y chabacana opulencia de sus millonarios, su fraudulenta propaganda, etc. Ya nos había advertido Antonio Machado en su Juan de Mairena de «la ola de ñoñez y americanismo» que invadiría la vieja Europa.

${ }^{41}$ Vid. al respecto Sandru-Olteanu (1970). 
extendido por diversos países, que mantiene en gran parte un nomadismo y han conservado rasgos físicos y culturales propios', respectivamente.

Como es natural, la transformación semántica que comentamos (conversión de un derivado mostrativo en signo léxico) no se produce de repente, sino que resulta de un proceso gradual más o menos prolongado, en que se distinguen por lo menos tres etapas distintas: a) Etapa de habla, en que el matiz conceptual del gentilicio presenta una existencia muy precaria, reducida exclusivamente a un ámbito de uso muy restringido, el ámbito de uso que lo vio nacer; b) Etapa de norma, en que, siempre vinculado a la significación mostrativa que le sirve de base, adquiere cierto grado de estabilidad en el discurso y amplía su ámbito de uso de forma más o menos considerable; y c) Etapa de sistema, en que pierde su vínculo con la significación mostrativa originaria y se convierte en signo léxico independiente.

En realidad, este fenómeno lingüístico no tiene nada de excepcional: su origen se encuentra en la capacidad que poseen los signos mostrativos unirreferenciales (nombres propios) para desarrollar significados léxicos particulares a partir de los conceptos que como todo nombre propio llevan asociados ${ }^{42}$. En efecto, tras el cambio semántico judio 'perteneciente o relativo a Judea', siamés 'perteneciente o relativo a Siam' y campechano 'perteneciente o relativo a Campeche'/ judio 'usurero', siamés 'dicho de un hermano, gemelo que nace unido por alguna parte de su cuerpo' y campechano 'que se comporta con llaneza y cordialidad sin imponer distancia en el trato' se encuentra la misma ley que permitió que los nombres propios don Quijote, don Juan, Celestina y Lazarillo por ejemplo, de designar a los conocidos personajes literarios que designan, pasaran a entenderse también como nombres comunes (quijote, donjuán, celestina y lazarillo), con la significación léxica respectiva de 'hombre que antepone sus ideales a su conveniencia y obra desinteresada y comprometidamente en defensa de causas que considera justas, sin conseguirlo', 'seductor de mujeres', 'mujer que concierta relaciones amorosas, alcahueta' y 'muchacho que dirige o guía a un ciego', que son características asociadas a los personajes aludidos.

De otro lado, tenemos que las personas naturales de un lugar determinado pueden designarse de forma léxica, mediante un signo descriptivo primitivo o derivado (o incluso una determinada combinación sintáctica), sin la más mínima relación semántica con el nombre de ese lugar, si es que este lo tiene. Por ejemplo, el sustantivo gato con que se designa a los naturales de Madrid; el adjetivo goloso con que se designa a los naturales de Santa María de Betancuria, en la isla de Fuerteventura; el adjetivo orejones con que designaron los españoles a varias tribus de América; el adjetivo gofiones con que empezaron a designar los tinerfeños a los naturales de Gran Canaria; o la expresión compleja ministro sin cartera con que se designa a los naturales de Bujalaro, en Guadalajara. Por lo general, se trata de nombres referidos a cualidades morales (tacañería, vanidad, gula, cobardía, pereza, terquedad...) o físicas (estatura, aseo, color ${ }^{43}$,

\footnotetext{
${ }^{42}$ Vid. al respecto Ullmann (1972).
}

${ }^{43}$ Un caso particular lo tenemos en el adjetivo negro con que aludimos a los grupos étnicos de piel negra y a las cosas a ellos pertenecientes o relativas (música negra, arte negro) y el adjetivo blanco con que aludimos a los grupos étnicos de piel blanca y a las cosas a ellos pertenecientes o relativas, aunque las 
tamaño del estómago, la nariz, las orejas, el culo, etc., aspecto del pelo...), habilidades, oficios, maneras de hablar, hábitos alimenticios, atuendos, etc. ${ }^{44}$, reales o imaginarios con que motejan los vecinos a la gente designada, generalmente por envidia, desprecio, rivalidad, resentimiento o simplemente humor ${ }^{45}$. Por ejemplo: al parecer, los naturales de Madrid se denominan gatos porque, en la conquista de la ciudad, uno de sus asaltantes «sin temer la resistencia que hacían los moros desde encima de las murallas, subió con tanta ligereza por una de ellas, hincando su daga en las junturas de las piedras, que los del Real, maravillados empezaron a decir que "parecía un gato"»" ${ }^{46}$ los naturales de la villa de Santa María de Betancuria, golosos, por la desmedida afición a la comida que les atribuye el resto de sus paisanos majoreros ${ }^{47}$; los miembros de las citadas tribus americanas, orejones, porque tenían las orejas grandes; los naturales de Gran Canaria, gofiones, porque comen gofio; los naturales de Bujalaro, ministros sin cartera, porque un hijo del pueblo (Alberto Martín Artajo) llegó a ser ministro de Asuntos Exteriores en los años 50-60 del siglo pasado ${ }^{48}$. De ahí el carácter burlesco, discriminatorio o irónico que los caracteriza y las connotaciones peyorativas que, incluso en los casos más bienintencionados, suelen presentar ${ }^{49}$. Las denominaciones calificativas que nos ocupan pueden tener su origen incluso en acepciones conceptuales de denominaciones gentilicias propiamente dichas. Es el caso del gallego con que se designa a los naturales del pueblo de Arcicóllar, en Toledo, o a los naturales del pueblo de Cedillo del Condado, en la misma provincia de Toledo; o del polaco con que, según vimos más atrás, se designa despectivamente a los catalanes. Lo principal en las denominaciones que consideramos no es, pues, el lugar al que pertenece la gente designada, sino más bien la cualidad, el comportamiento, la habilidad, etc., peculiares que se le atribuye. Cuando decimos que los naturales de Santa María de Betancuria son golosos, lo que interesa fundamentalmente no es el lugar en que estos nacieron, sino más bien la cualidad real o imaginaria que les atribuye la tradición: el ser aficionados a la comida; cuando los conquistadores españoles decían que los individuos de ciertas tribus americanas eran orejones, lo que les interesaba no era que estos habitaran un lugar determi-

gentes aquí aludidas no se caracterizan por pertenecer a un territorio determinado, sino más bien por su condición racial.

${ }^{44}$ Una relación más amplia de los argumentos más frecuentes de estas denominaciones puede verse en Morera (2011a: 111-120).

${ }^{45}$ Según Cela, «tres, al menos, pueden ser los orígenes del carácter peyorativo o denigrante de no pocos dictados: la cuna vecina — y natural y acostumbrada enemiga - de casi todos; la rima, caso de homoioteleuton que lleva a considerables despropósitos, y lo que nos permitimos llamar la inercia fónica» (1988: 65).

${ }^{46}$ Pedro de Répide, Las calles de Madrid, p. 35, cit. por de la Torre Aparicio (2005: 277) Los nombres de animales que aparecen en la función seudogentilicia que comentamos no tienen nada que ver con los nombres de animales que aparecen en las denominaciones totémicas: en aquellas, funciona como calificativo; en estas, como «padre de la estirpe», como señala Wundt, 1990: 107).

${ }^{47}$ Para lo relacionado con las distintas motivaciones semánticas de los seudogentilicios canarios, puede verse el exhaustivo y documentado catálogo de Ortega Ojeda (2008).

48 de la Torre Aparicio (2005: 113).

49 Esta condición de expresiones más o menos injuriosas, ofensivas o, cuando menos, burlescas, plantea un serio problema ético al lexicógrafo, dialectólogo, etnólogo o antropólogo que pretenda dar cuenta de ellas. Si se trata de expresiones injuriosas, ofensivas o burlescas, ¿hasta qué punto es legítimo contribuir a su propagación en obras científicas? 
nado, sino un rasgo concreto de su físico que les llamaba poderosamente la atención: el que estas gentes tuvieran las orejas grandes, en comparación con las propias.

Se ve, entonces, que el seudogentilicio, nombre que, por lo general, al contrario que los gentilicios, imponen los otros (denominaciones exógenas), no constituye un fenómeno lingüístico particular o episódico, sino un fenómeno lingüístico universal. Surge de la necesidad que tiene el hombre de definir a ese individuo que es su vecino, su otro más inquietante (por la proximidad), para dejar claras sus relaciones con él. En el seudogentilicio quedan fijados los términos de la relación de unos pueblos con otros, como, con toda la crudeza trágico-cómica que lo caracteriza, hizo ver Cervantes en el archiconocido episodio del rebuzno de su novela inmortal (capítulo XXV de la segunda parte), en que los vecinos de una aldea castellana terminan adquiriendo colectivamente el apelativo de del rebuzno por el virtuosismo que habían alcanzado dos de sus regidores en un arte que los de su condición suelen practicar con más frecuencia de la que debieran, que es rebuznar:

Y el diablo, que no duerme, como es amigo de sembrar y derramar rencillas y discordias por doquiera, levantando caramillos en el viento y grandes quimeras de no nada, ordenó e hizo que las gentes de los otros pueblos, en viendo a alguno de nuestra aldea, rebuznase, como dándoles en rostro con el rebuzno de nuestros regidores. Dieron en ello los muchachos, que fue dar en manos y bocas de todos los demonios del infierno, y fue cundiendo el rebuzno de uno en otro pueblo, de manera que son conocidos los naturales del pueblo del rebuzno como son conocidos y diferenciados los negros de los blancos; y ha llegado a tanto la desgracia de esta burla, que muchas veces con mano armada y formado escuadrón han salido contra los burladores los burlados a darse la batalla.

En estas líneas del genial escritor, quedan perfectamente trazadas, mucho mejor que en cualquier sesudo estudio filológico, las causas y las consecuencias de denominaciones tan singulares.

En su fase inicial, no existe, pues, relación alguna entre la denominación calificativa y el nombre del lugar en que viven las personas calificadas. De ahí la necesidad de expresarlo de alguna forma en el contexto lingüístico o en la situación extralingüística. Lo normal es que esta información locativa aparezca primero como componente del sujeto de los enunciados con seudogentilicio, en contextos muchas veces comparativos, del tipo los de Betancuria son unos golosos, las gentes de Cataluña hablan como polacos, los madrileños parecen gatos, etc.

De esta situación inicial, se pasa a otra en que la información toponímica se siente ya más o menos asociada al seudogentilicio, razón por la cual, cuando es necesario, puede expresarse en forma de complemento del nombre introducido por la preposición de: v. gr., los gatos de Madrid, los pejines de Santander, los golosos de la Villa ${ }^{50}$. Desde el punto de vista designativo, este sintagma preposicional puede entenderse en dos sentidos distintos: a) En sentido discriminador o partitivo: la gente designada por el

\footnotetext{
${ }^{50}$ Una copla del folklore tradicional de la isla dice así: «Si la mar fuera de leche, / y la tierra de tortilla, / no daría pa comer/ los golosos de la villa» (Navarro Artiles, s. f.).
} 
calificativo constituye solo una parte de los habitantes del lugar designado por el régimen preposicional. Es lo que sucede en el caso del pejín de expresiones como los pejines de Santander, que, según el DRAE, significa 'persona de humilde condición social de la ciudad española de Santander o de las poblaciones costeras de la provincia de Cantabria'; y b) En sentido ecuacional: la denominación afecta a todos los habitantes del lugar designado por el régimen preposicional. Es lo que sucede en el caso de las formas gato y goloso de combinaciones como los gatos de Madrid, los golosos de Santa María de Betancuria.

En una tercera fase de su evolución, por último, el contenido de lugar que hasta entonces había aportado el contexto lingüístico o la situación extralingüística se integra en la significación de la palabra, aunque en forma de connotación o evocación, no en forma de rasgo semántico inherente. Así, en una frase como Todos los golosos acudieron a la fiesta de San Buenaventura, donde goloso lleva ya asociada la significación toponímica de 'Santa María de Betancuria'; pero no como constituyente de su significación inherente, que es de naturaleza léxica, sino como connotación subordinada a esta. Hablando de los calificativos con que se motejan los habitantes de las islas canarias entre sí, escribía yo en 1990 lo siguiente:

No ocurre así (es decir, no pierden sus connotaciones burlescas) con los sobrenombres de los gentilicios de las Islas. Apodos como sogueros (los habitantes de Tindaya), ratones (los de Villaverde), corbatas (los de La Oliva), etc. (todos pueblos de Fuerteventura) siguen manteniendo hoy las mismas connotaciones peyorativas con que nacieron (Morera, 1990: 150).

$\mathrm{Y}$ siguen manteniendo esas connotaciones peyorativas porque conservan intacta su significación léxica invariante de "fabricante o vendedor de sogas", ${ }^{51}$, "mamífero roedor de unos dos decímetros de largo desde el hocico hasta la extremidad de la cola; de pelaje generalmente gris; muy fecundo y ágil y que vive en las casas, donde causa daño por lo que come, roe y destruye' y 'tira de seda u otra materia adecuada que se anuda o enlaza alrededor del cuello, dejando caer los extremos', respectivamente. No nos encontramos, por tanto, ante denominaciones gentilicias propiamente dichas, ante denominaciones que presentan a la gente designada como caracterizadas por el lugar que habitan, sin más, sino ante denominaciones calificativas con orientación locativa. De ahí el nombre de seudogentilicios con que las bautizó Camilo José Cela (1988: 51-54), uno de los primeros en llamar la atención sobre este importante material onomástico ${ }^{52}$.

${ }^{51}$ Que la significación léxica del término permanece viva en la conciencia del hablante lo pone de manifiesto el hecho de que el seudogentilicio se siga relacionando con su base derivativa $\operatorname{sog} a$, como se observa en la siguiente coplilla del folklore popular de Fuerteventura: «En Tindaya se hacen sogas; / en La Matilla, cordones;/ en el pueblo Vallebrón, / teniques y garrafones» (véase F. Navarro Artiles, s. f.).

${ }^{52} \mathrm{Se}$ trata, en realidad, de una parte de lo que se ha dado en llamar dictados tópicos, que abarca todos los dichos locales en que se manifiestan las filias y las fobias de las gentes y de los pueblos. Al parecer, el primero en prestar atención a este material folklórico en nuestro ámbito cultural fue el portugués José Leite de Vasconcellos (1882). Poco después aparecerá el trabajo de Joaquín Costa (1883-1884). Ya en el siglo XX, verá la luz la obra de Antonio Rodríguez Moñino (1933). 
Las principales consecuencias referenciales y textuales de la particular forma de significar de los seudogentilicios son las siguientes:

Primera, que, cuando concurren con el gentilicio que les corresponde en un mismo sintagma o frase atributiva, actúan más como complemento (los madrileños son gatos, los betancurianos son golosos, los de San Sebastián de La Gomera son legañosos) que como núcleo. En las lenguas naturales, es el signo descriptivo el que complementa al signo mostrativo, no a la inversa. De ahí la extrañeza semántica que producirían frases como las siguientes: los gatos son madrileños, los golosos son betancurianos, los legañosos son de San Sebastián de La Gomera, donde el seudogentilicio funciona como sujeto y el signo mostrativo como atributo.

Segunda, que se entiendan siempre, o casi siempre, como denominaciones peyorativas de las personas designadas: la toma de postura que implica la definición de un grupo humano al que corresponde de forma natural una aséptica definición mostrativa mediante una determinada denominación descriptiva referida a alguna característica de su aspecto, comportamiento, historia, actividad, etc., resulta tan parcial, que no puede dejar de interpretarse como agresión a la intimidad de las personas designadas. De ahí que, salvo en situaciones de comunicación más o menos informales o humorísticas, los seudogentilicios sean generalmente rechazados por las personas aludidas por ellos.

Tercera, que, como denominación calificativa que es, agote su capacidad designativa en la persona o grupo de personas aludido. En principio, el seudogentilicio no se puede aplicar a los animales, las plantas, los minerales, los fenómenos naturales, etc., de los lugares designados, sino a las personas, precisamente porque, por lo general, no es relación con el lugar externamente aludido lo que significa formalmente, sino cualidad personal. Por eso, resultaría absurdo hablar de clima gato, la gata calle de Alcalá o gobierno autónomo gato para referirnos al clima, a la calle de Alcalá o al gobierno autónomo de Madrid; o de cabras golosas, queso goloso o artesanía golosa para referirnos a las cabras, el queso y la artesanía de Santa María de Betancuria. Esto quiere decir que el seudogentilicio no se puede definir en ningún caso como 'perteneciente o relativo' al lugar aludido.

La forma de significar de las dos clases de palabras que nos ocupan, es decir, el hecho de que estas definan a los grupos humanos más por lo que son en sí mismo y por sí mismos, por algún rasgo de su físico o su comportamiento, que por su perteneciente a un territorio, explica que se trate de las primeras denominaciones de gens de las lenguas naturales ${ }^{53}$. En principio, lo relevante para la identidad del grupo humano, antes de que se tomara conciencia de la importancia de la familia, el tótem o el territorio, era su comportamiento colectivo, o alguna cualidad moral o física sobresaliente, generalmente advertida por los pueblos vecinos. Por ejemplo, sabemos que el nombre hotentote con que se designa a los individuos de una nación indígena que habitó cerca del cabo de Buena Esperanza procede del adjetivo neerl. hotentot 'tartamudo'; el nombre cafre con que se designa a los habitantes de la antigua colonia inglesa de Cafrería, en Sudá-

${ }^{53}$ Se trata de un procedimiento que está en la base de muchos de los gentilicios de los llamados pueblos bárbaros de Europa (alamanes, suevos, vándalos, magiares, burgundios, francos, etc.), africanos (hotentote, cafre, bubi, bosquimano, pigmeo, etc.), etc. 
frica', del adjetivo árabe kabir 'pagano'; el nombre pigmeo con que se designa a cierto pueblo fabuloso, del adjetivo griego pygmaios 'pequeño'; el nombre bosquimano con que se designa a los individuos de una tribu del África meridional, al norte de la región del Cabo, del nombre afrikáans boschjesman 'hombre del bosque'; etc.

Lo comentado hasta aquí pone claramente de manifiesto hasta qué punto gentilicios y seudogentilicios constituyen dos clases de palabras radicalmente distintas: el gentilicio es un adjetivo de relación derivado de un signo mostrativo-espacial unirreferencial (topónimo), que, en sí mismo y por sí mismo, carece de información descriptiva, si dejamos al margen las circunstanciales evocaciones que, como todo nombre propio, conlleva; el seudogentilicio es una denominación descriptiva absoluta de las personas que ocupan un lugar determinado, un nombre descriptivo totalmente ajeno a la mostración. Por eso, ambos tipos de palabras desempeñan funciones semánticas diferentes: el gentilicio se limita a vincular de forma neutra, sin ninguna concesión a la conceptualización, a las personas, y también a los animales, las plantas, los minerales, los fenómenos naturales, etc., con el lugar en que nacieron, se criaron, se produjeron, etc. El vínculo entre los elementos del grupo es el territorio. Betancuriano es el que lleva dentro del concepto de Santa María de Betancuria; el seudogentilicio, al contrario, conceptualiza o califica (y valora, por tanto) de una determinada manera a las personas que ocupan el lugar aludido por el contexto. El vínculo entre los elementos del grupo lo proporciona una determinada forma de comportarse, una rasgo físico o moral, una determinada circunstancia histórica, etc., compartidos. Goloso es una simple cualidad, ajena internamente a toda noción espacial o territorial. Lo que quiere decir que las palabras que consideramos no son en realidad falsos gentilicios, como indica el nombre que se suele emplear para designarlos, sino otra forma de significar los grupos humanos, aunque generalmente de menor rango que aquel. Por eso sería mejor hablar de parangentilicio $^{54}$, de adjunto al gentilicio, que de seudogentilicio.

Se ve, pues, que el seudogentilicio es al gentilicio lo mismo que el apodo al nombre propio de persona. De ahí que algunos autores los hayan denominado también con el nombre de gentilicios apodo ${ }^{55}$. Cuando denomino a alguien por su nombre propio (Juan o María, por ejemplo), lo que hago es identificarlo, sin más; cuando lo denomino mediante un mote, apodo o nombrete (camella, sargo, higo, por ejemplo), lo que hago es describirlo ${ }^{56}$. Por eso precisamente, el gentilicio, ajeno en su función denominadora básica a la conceptualización, actúa como denominación oficial o formal, en tanto que el seudogentilicio, con toda la carga descriptiva que moviliza, actúa como denominación oficiosa o informal. Así, de las dos denominaciones (betancurianos (o villeros) y golosos) que se atribuye a los naturales de Santa María de Betancuria, la gentilicia

${ }^{54}$ Cela emplea este nombre para aludir a los gentilicios que no derivan directamente del nombre del lugar, sino de alguna circunstancia suya: v. gr., el porteño (frente a bonaerense) con que se designa a los naturales de Buenos Aires y el ribereño (frente a arajovense o arancetano) con que se designa a los naturales de Aranjuez (1988: 51).

${ }^{55}$ Además del citado Cela, es también el caso de Morera (1990: 150), Ortega Ojeda (2008: 2231), Sánchez Salas (2009: 65-79) y Barcia (2010: 27-34).

${ }^{56}$ En relación con el concepto general de apodo, vid. Morera (1999: 115-116). 
(betancuriano (o villero)) constituye su nombre oficial o formal, mientras que la seudogentilicia (goloso) constituye nombre oficioso o informal.

Pero, a pesar de que gentilicio y seudogentilicio son unidades lingüísticas de naturaleza semántica radicalmente distintas, la realidad es que, con el paso del tiempo, este puede adquirir la condición semántica de aquel. Más todavía: todo seudogentilicio nace con vocación gentilicia, de convertirse en el nombre verdadero de las personas a que alude. ¿De qué manera en concreto se transforman los seudogentilicios en gentilicios? Pues degradando a la condición de significación connotativa la significación invariante descriptiva que lo caracteriza, y elevando a la categoría de componente semántico fundamental el sentido mostrativo-espacial unirreferencial que lleva asociado. Es lo que sucedió en el caso de los antiguos seudogentilicios franco, turco, bereber, conejero, chicharrero, yanqui, maño y gaucho, por ejemplo, que, de ser meras denominaciones calificativas ("libre, independiente, ${ }^{, 57}$, 'fuerte, ${ }^{58}$, 'de habla ininteligible',59, 'abundante en conejos ${ }^{60}$, 'que se alimenta de chicharros ${ }^{, 61}$,' 'Juan queso' ${ }^{62}$, 'cautivado, sometido' ${ }^{63}$ y 'borrachín ',64, respectivamente) de los habitantes de Francia, Turquía, Norte de África, Lanzarote, Santa Cruz de Tenerife, Estados Unidos de América, Aragón y La Pampa, han pasado a significarlos de forma mostrativa, convirtiéndose así en denominaciones propiamente gentilicias, más o menos en pie de igualdad con los gentilicios formales, en caso de que estos existan. Lo que ha ocurrido aquí son dos cosas distintas. La primera de ellas es que los contenidos mostrativos o identificadores 'Francia', 'Turquía', 'Norte de África', 'Lanzarote', 'Santa Cruz de Tenerife', 'Estados Unidos de América', 'Aragón' y 'La Pampa', que actuaban originariamente como meras connotaciones asociadas a la significación léxica o descriptiva de estos signos, se han convertido en rasgo fundamental o esencial de la palabra. En esta nueva situación, franco no significa ya 'libre, independiente', sino 'perteneciente o relativo a Francia'; turco no significa 'fuerte', sino 'perteneciente o relativo a Turquía'; bereber no significa 'de habla incomprensible', sino 'perteneciente o relativo al Norte de África'; conejero no significa 'abundante en conejos', sino 'perteneciente o relativo a Lanzarote'; chicharrero no significa 'que consume muchos chicharros', sino 'perteneciente o relativo a

${ }^{57}$ Del calificativo * frank 'libre, independiente' que se daba a los pueblos germanos de Franconia y del bajo Rin, porque, según algunos, no se sometieron nunca a los romanos.

${ }^{58}$ Del adjetivo turco türk 'fuerte', con que se calificaban a sí mismas las gentes aludidas.

${ }^{59}$ Del árabe marroquí berber, y este de la onomatopeya del árabe clásico expresiva del barboteo barbar, que atribuían los árabes a los bereberes porque no entendían su lengua.

${ }^{60}$ Calificativo que se dio a la isla de Lanzarote por la plaga de conejos que la asoló inmediatamente después de la conquista europea (Morera, 2007c: s. v.).

${ }^{61}$ Nombre con que motejaban los habitantes de La Laguna, en Tenerife, a los habitantes de Santa Cruz, por la enorme cantidad de chicharros (pez muy humilde de las costas canarias) que estos consumían (Morera, 2007c: s. v.).

${ }^{62}$ Según algunos, esta voz deriva del nombre propio neerlandés Jan Kaas ('Juan Queso'), que se terminó generalizando como seudogentilicio de los naturales de la Nueva Inglaterra, por la enorme cantidad de emigrantes holandeses que se asentaron en esta parte de los Estados Unidos de América.

${ }^{63}$ Según algunos, la etimología más verosímil de maño es el árabe manuw 'cautivo, sometido, humillado', con que calificaban los musulmanes a los aragoneses en la Edad Media.

${ }^{64}$ Según Morínigo (1966: s. v.) del guaraní ca'úcho 'borrachín', con que designaban los indios a los changadores que les robaban el ganado. 
Santa Cruz de Tenerife'; yanqui no significa 'Juan Queso', sino 'perteneciente o relativo a los Estados Unidos de América'; maño no significa 'cautivo, sometido', sino 'perteneciente o relativo a Aragón'; y gaucho no significa 'borrachín', sino 'perteneciente o relativo a La Pampa'.

Claro que el valor léxico de los seudogentilicios no desaparece de la noche a la mañana, sino que pasa por una etapa intermedia, en que pervive como mera connotación, asociada a la nueva significación mostrativa del término. Concretamente, en el caso de los gentilicios canarios conejero y chicharrero, se atisban todavía ecos lejanos de sus antiguos valores derivados de los signos léxicos conejo y chicharro, respectivamente. En esta situación de rasgo semántico secundario puede sobrevivir la antigua significación descriptiva más o menos tiempo. El gentilicio bereber, por ejemplo, mantiene todavía restos de su originario valor peyorativo, como pone de manifiesto el hecho de que sea una denominación todavía no bien vista por la gente que designa, que prefiere usar el apelativo propio amazigh. De esta manera quedan invertidos los papeles que jugaban significación mostrativa y significación descriptiva en la estructura semántica de la forma originaria: la significación mostrativa, que era secundaria, pasa a primaria, y la significación léxica, que era primaria, pasa a secundaria. Una de las pruebas más evidentes de la desaparición de la significación léxica de los seudogentilicios es que, una vez consumado el proceso semántico que comentamos (conversión del signo descriptivo en signo mostrativo), en muchas ocasiones, ni siquiera es posible determinar con exactitud qué significación léxica concreta correspondía en sus orígenes a estos signos. De ahí la enorme cantidad de especulaciones etimológicas más o menos peregrinas que han suscitado antiguos seudogentilicios como hispano ${ }^{65}$, maño $^{66}$ o gaucho $^{67}$, por ejemplo.

Es evidente, pues, que el seudogentilicio se transforma en gentilicio convirtiendo en rasgo fundamental de su significación el contenido mostrativo-espacial unirreferencial que implica. Por eso, no constituye ningún disparate afirmar que, como la base semántica de los gentilicios navarro, chino, uruguayo, canario, palestino, gomero y argentino, por ejemplo, son Navarra, China, Uruguay, Canaria, Palestina, La Gomera y Argentina, la base semántica de los gentilicios procedentes de paragentilicios hispano y turco, por poner solo dos ejemplos, son, respectivamente, *Hispana y *Turca, que, exactamente igual que aquellos, implican una geografía, una gente, una flora, una fauna, unos fenómenos naturales, etc., propios, geografía, gente, flora, fauna, fenómenos naturales, etc., que se expresan mediante los gentilicios hispano y turco. La única diferencia que se aprecia entre estos dos tipos de signos es que la base toponímica de los primeros tiene existencia independiente y la de los segundos, no. ¿De dónde surge este supuesto topónimo? Pues del mismo concepto de gentilicio, que obliga a interpretar su

${ }^{65}$ Unos piensan que procede de la raíz fenicia spn, que interpretan como 'conejo', 'oculto' o 'norte'; otros, que podría proceder de la raíz también fenicia spy 'forjar o batir metales'; para otros, se trata del griego esperos 'primera estrella'; y para otros, del vasco Izpania 'parte del mundo'.

${ }^{66}$ Según algunos, del árabe manuw 'cautivo, sometido', como vimos antes. Para otros, se trataría del latín magnus 'grande'. Otros consideran que deriva de la voz hermano, por aféresis.

${ }^{67}$ Para Morínigo (1966: s. v.), del guaraní ca'úcho 'borrachín', como vimos más arriba. Para otros, del mapuche guacho 'huérfano, desvalido'. 
base como tal. Digamos que *Hispana y *Turca constituyen la base toponímica de los gentilicios hispano y turco por definición. Frente a la adjetivación que implica la conversión del topónimo en gentilicio, tenemos la sustantivación interna que implica la conversión del seudogentilicio en gentilicio. La condición para que el seudogentilicio se convierta en gentilicio es que se transforme en nombre propio de lugar. Hasta tal punto convierten los seudogentilicios en inherente el contenido toponímico aludido, que, en algunos casos, los hablantes terminan proporcionando a este existencia independiente. Es el caso del citado chicharrero, que, en registros idiomáticos más o menos informales de la isla de Tenerife, ha desarrollado la forma El Chicharro para referirse al lugar en que habitan las personas que designa; o de canario, que se sustantivó en la forma Canaria para dar nombre a la patria de la gente designada. Por lo general, antes de convertirse en topónimo, el seudogentilicio suele pasar por una fase intermedia en que actúa como simple atributo del lugar designado: tierra (isla) canaria $\rightarrow$ Canaria. En estos casos, se produce un fenómeno singular: aunque diacrónicamente el gentilicio precede al topónimo (históricamente sabemos que los topónimos El Chicharro y Canaria derivan de los gentilicios chicharrero y canario), sincrónicamente el hablante interpreta que el topónimo precede al gentilicio: los gentilicios chicharrero y canario derivan de los topónimos El Chicharro y Canaria.

Tenemos, pues, que, exactamente igual que los gentilicios primarios, los gentilicios procedentes de seudogentilicios se conciben como adjetivos derivados de topónimos, del topónimo que se encuentra encerrado en su base. Las diferencias que se observan entre unos y otros son de rango secundario. De un lado, los gentilicios primarios suelen derivar del topónimo mediante derivación, mientras que los gentilicios procedentes de seudogentilicios, como también ciertos gentilicios primarios, derivan del topónimo por adjetivación, que es el tipo de derivación nominal más elemental que existe, porque se limita a degradar el nombre de lugar a rasgo simple o cualidad. De ahí que se pueda decir, sin temor a equivocarse, que los gentilicios derivados de seudogentilicios y algunos gentilicios primarios, como los citados navarro, palestino, gomero, canario, etc., son los gentilicios más simples que existen, porque solo se diferencian del nombre de lugar de su base en la significación categorial. De otro lado, el gentilicio primario se diferencia del gentilicio procedente de seudogentilicio en que, en el caso de aquel, el topónimo preexiste al gentilicio, mientras que, en el caso de este, el topónimo lo crea el gentilicio, tanto si adquiere independencia como si no.

De todas formas, hay que tener en cuenta que, aunque el topónimo que se encuentra en la base del gentilicio procedente de seudogentilicio puede independizarse y funcionar como verdadero topónimo, lo normal es que el nombre del lugar designado se forme a partir del gentilicio mediante el sufijo $-i a^{68}$. Es lo que sucedió en el caso de nues-

${ }^{68}$ Vid. Morera (2011). Se trata del mismo sufijo que encontramos en gentilicios como egipcio 'perteneciente o relativo a Egipto' o lesbio 'perteneciente o relativo a la isla de Lesbos'. Por tanto, desde el punto de vista más estrictamente morfológico, los topónimos Rusia ('emanación activa del concepto ruso') y Francia ('emanación activa del concepto franco'), por ejemplo, tienen exactamente la misma estructura semántica que egipcio ('emanación activa del concepto Egipto') y lesbio ('emanación activa del concepto Lesbos'), aunque los primeros sean topónimos y los segundos gentilicios. La diferencia que existe entre unos y otros no es de significación, sino de sentido: Rusia y Francia se interpretan como nombres de lugar 
tros ejemplos hispano y turco, que desarrollaron los derivados Hispania (que evolucionó a España, por palatalización de la nasal, por efecto de la yod) y Turquía para referirse a la patria de los hispanos y los turcos, respectivamente; como jordano 'perteneciente o relativo al Jordán' desarrolló el derivado Jordania para referirse a la patria de los jordanos; o el gentilicio romano 'perteneciente o relativo a Roma', que se había extendido a designar a los naturales de la Dacia, desarrolló el derivado Rumanía para designar el conocido país centroeuropeo. En realidad, se trata del mismo proceso derivativo que permitió crear los nombres de nación India y Nigeria a partir de los nombres de río Indo y Níger, el nombre de nación Colombia, a partir del nombre propio de persona Colombo (Colón), y el nombre de nación Liberia, a partir del adjetivo libre ${ }^{69}$. Nos encontramos, por tanto, ante nombres derivados que no se confunden, ni mucho menos, con el topónimo primitivo que se encuentra en la base del gentilicio: Hispania y Turquia, como Jordania, Rumanía, India, Nigeria, Colombia y Liberia, no son nombres primitivos, sino nombres derivados de nombres o adjetivos, que significan respectivamente 'lo que emana activamente del concepto hispano', 'lo que emana activamente del concepto turco', 'lo que emana activamente del concepto jordano', 'lo que emana activamente del concepto rumano', 'lo que emana activamente del concepto Indo', 'lo que emana activamente del concepto Níger', 'lo que emana activamente del concepto Colombo (Colón)' y 'lo que emana activamente del concepto libre' ${ }^{, 70}$. Por eso, no se puede decir que la relación que los gentilicios navarro, chino, uruguayo, palestino, gomero, argentino y chicharrero guardan con sus topónimos Navarra, China, Uruguay, Palestina, La Gomera, Argentina y El Chicharro sea la misma que la que guardan los gentilicios hispano, turco, rumano, jordano y ruso con el que se les atribuye habitualmente (España, Turquía, Rumanía, Jordania y Rusia): en los primeros, el gentilicio deriva del topónimo; en los segundos es a la inversa.

Se trata de un hecho que hay que tener muy en cuenta en la definición lingüística de estos signos. Por una parte, tenemos que las formas navarro, chino, uruguayo, canario, palestino, gomero, argentino y chicharrero pueden definirse, sin problemas, a partir de sus topónimos independientes Navarra, China, Uruguay, Canaria (y, por extensión, Canarias), Palestina, La Gomera, Argentina y El Chicharro, respectivamente. Así, se puede decir que navarro significa 'perteneciente o relativo a Navarra'; chino, 'perteneciente o relativo a China'; uruguayo, 'perteneciente o relativo a Uruguay'; canario, 'perteneciente o relativo a Canaria' y 'perteneciente o relativo a Canarias'; palestino,

('patria de los rusos' y 'patria de los francos'), porque proceden de denominaciones gentilicias; egipcio y lesbio, como gentilicios ('perteneciente o relativo a Rusia' y 'perteneciente o relativo a Lesbos'), porque proceden de topónimos. Muy raramente encontramos otros sufijos en esta función derivativa, como el caso de Bélgica, derivado del gentilicio belga mediante el sufijo -ico.

${ }^{69}$ En ciertas lenguas, los nombres de países o regiones se construyen de forma compositiva. Es el caso de las lenguas germánicas, que los construyen con el término land 'tierra' (Iceland, Scotland, Finland., Groenland, Suitzerland, Deutschland...); de determinadas lenguas asiáticas, que los construyen con el término de origen persa -stan 'zona o lugar': Turquestán, Pakistán, Afganistán; o de determinadas lenguas mejicanas, como el náhuatl, que los construye con la partícula -tlan 'lugar' (Acaxuchitlán, etimológicamente 'lugar en que abunda el acaxochitl', Acatlán, etimológicamente 'lugar de cañas'...), entre otras.

${ }^{70}$ También pueden entenderse los derivados en -ía de los gentilicios como nombres de cualidad, como españolía, que se entiende como 'cualidad de español'. 
'perteneciente o relativo a Palestina'; gomero, 'perteneciente o relativo a La Gomera'; argentino, 'perteneciente o relativo a Argentina'; y chicharrero, 'perteneciente o relativo a El Chicharro'. Por otra, las formas hispano, turco, rumano, jordano y ruso, por ejemplo, no se pueden definir a partir de sus topónimos independientes España, Turquía, Rumanía, Jordania y Rusia, respectivamente. Desde el punto de vista más estrictamente idiomático, no se puede decir que hispano signifique 'perteneciente o relativo a España', turco, 'perteneciente o relativo a Turquía', rumano, 'perteneciente o relativo a Rumanía', jordano, 'perteneciente o relativo a Jordania', y ruso, 'perteneciente o relativo a Rusia'. Y no se puede decir esto porque el gentilicio que se pretende definir está contenido en el nombre de lugar que se emplea para definir. Por eso, lo más coherente en estos casos es definir a partir del topónimo integrado en el gentilicio, y analizar luego el topónimo derivado a partir del gentilicio. Concretamente, en los casos citados diríamos que hispano significa 'perteneciente o relativo a *Hispana'; turco, 'perteneciente o relativo a *Turca'; rumano, 'perteneciente o relativo a *Rumana'; jordano, 'perteneciente o relativo a "Jordana'; y ruso, 'perteneciente o relativo a *Rusa'.

¿Que Hispana, Turca, Rumana, Jordana y Rusa no existen como sustantivos independientes en español? Es verdad. Pero sí existen como elemento interno, como constituyente fundamental de una clase de palabras que se define precisamente por su condición de adjetivo derivado de un topónimo. La falta de independencia de las bases no constituye ninguna rareza en la formación del vocabulario de una lengua, como ponen de manifiesto el caso de las palabras españolas desratizar, conducir, inferir, cacería, panadero, etc., cuyas bases *ratizar, *ducir, *ferir, *cacero y *panada carecen de existencia independiente. Ya había advertido Coseriu que «no es necesario que cada grado de una serie esté efectivamente "realizado" por una palabra existente en la lengua: al. Freundschaft supone un adjetivo "anterior" que no existe en la norma alemana» ${ }^{71}$. Así, el orden de los elementos perteneciente a las series lingüísticas que nos ocupan sería el siguiente: topónimo primitivo (*Hispana, *Turca, *Rumana, *Jordana y *Rusa), que, a pesar de carecer de existencia independiente, constituye el punto de partida o elemento básico de la serie; gentilicio (hispano, turco, rumano, jordano y ruso), que proceden del topónimo primitivo por derivación adjetiva; y topónimo derivado (Hispania, Turquía, Rumanía, Jordania y Rusia), que procede del gentilicio por derivación morfológica ${ }^{72}$. Obviamente, no ocurre así en el caso de series como Sevillasevillano, donde no hay más que dos elementos: el topónimo primario Sevilla, que

${ }^{71}$ Coseriu (1977: 139); vid. también Morera (2005: 13).

${ }^{72}$ La cadena puede ser incluso más compleja, como ponen de manifiesto la serie bohemo (gentilicio primitivo), Bohemia (topónimo derivado del gentilicio primitivo), bohemio (gentilicio derivado del topónimo derivado por adjetivación) y bohemiano (gentilicio derivado del topónimo derivado por derivación morfológica); la seria siro (gentilicio primitivo), Siria (topónimo derivado del gentilicio primitivo), sirio (gentilicio derivado del topónimo derivado por adjetivación) y siriano y siriaco (gentilicios derivados del topónimo derivado por derivación morfológica); la serie turco (gentilicio primitivo), Turquía (topónimo derivado del gentilicio primitivo) y turquí y turquino (gentilicios derivados del topónimo derivado por derivación morfológica); o la serie tésalo (gentilicio primitivo), Tesalia (topónimo derivado del gentilicio primitivo), tesalio (gentilicio derivado del topónimo derivado por adjetivación) y tesaliense y tesálico (gentilicios derivados del topónimo derivado por derivación morfológica). 
tiene existencia independiente y actúa como punto de partida o elemento básico de la serie; y el gentilicio sevillano, derivado morfológico de aquel. Todo esto quiere decir que, en buena lógica gramatical, el gentilicio de topónimos derivados como Turquía, Rusia, etc., no son turco y ruso, respectivamente, sino turqués, turquino, turquesco (*turquio, *turquiano, *turqués, *turquiero...) y *rusio (*rusiano, *rusiés, *rusiero...), como los gentilicios de los topónimos derivados Siria, Italia, Austria y Libia son sirio, italiano, austriaco y libio, también respectivamente. Puede ocurrir, incluso, que un topónimo desarrolle dos o más gentilicios, uno por derivación adjetiva y otros por derivación morfológica. Es el caso de los topónimos California, Frisia y Estonia, por ejemplo, que han dado, por derivación adjetiva, los gentilicios californio, frisio y estonio, y, por derivación morfológica, los gentilicios californiano, frisón y estoniano. ¿Se trata de gentilicios sinónimos? En absoluto: californio, frisio y estonio expresan la relación con el topónimo categorialmente, adjetivando el nombre; californiano, frisón y estoniano, morfológicamente, expresando una determinada relación con él. Por eso, el primero se siente más interno al sustantivo que lo rige (actor californio) que el segundo (actor californiano).

Sabido es que la lexicografía tradicional define estos gentilicios a partir del topónimo derivado. Así nos dice que turco significa 'perteneciente o relativo a Turquía'; ruso, 'perteneciente o relativo a Rusia'. Y define a partir del topónimo derivado porque considera que los gentilicios correspondientes son derivados regresivos de él. Aunque, desde el punto de vista práctico, tal vez no quede otro remedio que hacerlo así, porque es el tipo de definición que resulta más clara para la persona que consulta el diccionario, la solución es lingüísticamente indefendible, tanto sincrónica como diacrónicamente. Sincrónicamente, porque, como hemos demostrado más arriba, el topónimo que se encuentra en la base semántica de estos gentilicios no es un topónimo derivado, sino un topónimo primitivo, aunque este carezca de existencia independiente. Diacrónicamente, la solución es inviable, porque está demostrado que, de las dos formas consideradas (gentilicio y topónimo en -ía correspondiente), la más antigua de ellas es la forma gentilicia, en tanto que la forma toponímica ha surgido mucho después a partir de aquella. En realidad, esta teoría de la derivación regresiva no convence ni siquiera a los que suelen propugnarla teóricamente y aplicarla prácticamente. Así, la Academia, que, a juzgar por la forma de definir estos gentilicios en su diccionario, no ha dudado en tratarlos como derivados regresivos, considera en su Nueva gramática que

en estos casos puede también concebirse el proceso morfológico en la dirección opuesta a la que suele ser habitual, es decir, con el gentilicio como base y el topónimo como derivado, ya que los territorios de los que se habla se caracterizan a partir de individuos que los pueblan (Francia designa el territorio de los francos, no al contrario). De hecho, en la morfología sincrónica son defendibles procesos como birmano>Birmania o sueco $>$ Suecia, que algunos autores postulan frente a los que defienden la dirección inversa (Real Academia Española, 2009: 538-539).

Más discutible todavía es la práctica de definir el gentilicio a partir de un topónimo que absolutamente nada tiene que ver con aquel desde el punto de vista lingüístico. Es lo que sucede en el caso de chicharrero, que los diccionarios definen como 'pertene- 
ciente o relativo a Santa Cruz de Tenerife'; de conejero, que definen como 'perteneciente o relativo a Lanzarote'; de guanche, definido como 'perteneciente o relativo a las Islas Canarias'; o de majorero, definido como 'perteneciente o relativo a Fuerteventura'. Evidentemente, se trata de definiciones referenciales que no dan cuenta de la verdadera significación lingüística de estas unidades. Como hemos señalado más arriba, desde el punto de vista de la lengua, lo que significa chicharrero no es 'perteneciente o relativo a Santa Cruz de Tenerife', sino 'perteneciente o relativo a El Chicharro'; conejero no significa 'perteneciente o relativo a Lanzarote', sino 'perteneciente o relativo a *El Conejo (o *Conejera ${ }^{73}$ '); guanche no significa 'perteneciente o relativo a las Islas Canarias', sino 'perteneciente o relativo a *Guancha'; majorero no significa 'perteneciente o relativo a Fuerteventura', sino 'perteneciente o relativo a Maxorata'. Desde el punto de vista de la norma, Fuerteventura carece de gentilicio, aunque, desde el punto de vista del sistema, este muy bien pudiera ser fuerteventuro, fuerteventurano, fuerteventureño, fuerteventurés, fuerteventurero, fuerteventurense, etc., que no se han actualizado en la norma hasta hoy. Unamuno usó alguna que otra vez el también posible fuerteventuroso ${ }^{74}$, que no ha tenido fortuna ${ }^{75}$. Vistas las cosas desde la perspectiva del idioma, es claro que a los majoreros no los define la moderna Fuerteventura; los define la vieja Maxorata.

Pues bien, una vez que el seudogentilicio deviene en gentilicio, en adjetivo de relación de un nombre de lugar determinado; es decir, una vez que ha formalizado la significación invariante 'perteneciente o relativo al lugar implicado en la base', ocurren cuatro cosas distintas:

Primera, que pierde, o disminuye considerablemente, no solo su significación léxica originaria, sino también las connotaciones negativas asociadas a ella, y se convierte en denominación más o menos aséptica de las personas designadas, como ponen de manifiesto las mismas definiciones que de ella proporcionan los diccionarios. Así, según Marcos Morínigo, el actual gaucho no tiene ya nada que ver con su originaria significación léxica de 'borrachín', ni con las connotaciones que a esa significación se asociaban, sino que significa más concretamente 'hombre del campo de Río de la Plata' (1966: s. v.); según la Academia Canaria de la Lengua, los gentilicios canarios conejero y chicharrero no tienen ya absolutamente nada que ver con su significación léxica

${ }^{73}$ Aunque lo consigno con asterisco, se trata de un nombre existente en español. Concretamente, aparece como título de un poemario de Manuel Padorno, publicado en 1963. «Conejera — nos dice Alejandro González, editor de Padorno - es, en fin, heterónimo para la isla de Lanzarote, a la que el poeta marchó recién casado con Josefina Betancor y donde escribiría A la sombra del mar, luego Conejera. Todos los topónimos que aparecen en este poemario refieren localizaciones a la isla de Lanzarote» (Padorno, 2011: 161, nota del editor).

${ }^{74}$ En nota al soneto XVI de De Fuerteventura a Paris, escribe don Miguel: «Los campesinos majoreros o fuerteventurosos viven principalmente de gofio, harina de maíz o trigo — o mezcla de ambostostado primero y luego molido en molino de viento». Antes, en el primer cuarteto del soneto VIII del mismo libro había dicho: «¡Oh, fuerteventurosa isla africana, / desnuda y descarnada cual camello, / en tu mar piadosa vi el destello / del sino de mi patria. Mar que sana».

${ }^{75}$ Solamente aparece en algún que otro escrito de sus seguidores majoreros, como el cura de Puerto del Rosario Víctor San Martín, que en una carta de 1932 remitida al autor dice lo siguiente: «No quiero alargarme más, querido don Miguel. Que usted goce de tan buena salud como gozo en esta isla fuerteventurosa y que siga trabajando con éxito feliz por nuestra amada patria» (Morera, 2000: 106). 
originaria de 'abundante en conejos' y 'que come chicharros', ni con las connotaciones peyorativas originariamente a ellas asociadas, sino que significan más concretamente 'perteneciente o relativo a Lanzarote' y 'perteneciente o relativo a Santa Cruz de Tenerife' (2010: s. v.). Hasta tal punto han desaparecido tanto la significación léxica de 'que come chicharros' como las connotaciones peyorativas a ella asociadas en el caso de chicharrero, que los grancanarios, rivales de los tinerfeños en el pleito insular, se han visto obligados a achicar la denominación en el hipocorístico chicha, para devolverle a esta parte de sus viejas connotaciones ofensivas o burlescas ${ }^{76}$. La transformación en derivado de topónimo eleva el seudogentilicio a la categoría de palabra decente, sin ningún tipo de connotación peyorativa: i. e., el seudogentilicio se dignifica con su gentilización. En las condiciones semánticas que consideramos, no hay razón alguna para que la denominación gentilicia sea rechazada por las personas que designa, que es lo que ocurría en su fase de seudogentilicio. Todo lo contrario: el carácter particular de la nueva palabra, el hecho de que esta bautice el lugar designado de manera inédita, singularizándolo aún más, si cabe, determina que sus titulares no solamente la asuman con absoluta normalidad, sino que, a veces, lo hagan con ostentoso orgullo. En su estado actual, gaucho, conejero y chicharrero, por ejemplo, no son voces con que denominan despectivamente a los naturales de La Pampa, Lanzarote y Santa Cruz de Tenerife, respectivamente, gentes extrañas al grupo, sino nombres con que se definen a sí mismos los gauchos, conejeros y chicharreros. Es más: en relación con los naturales de Lanzarote, conozco gentes de la isla que manifiestan que ellas no son solo lanzaroteñas, sino conejeras, como si entendieran que el conejero es más de la tierra que el lanzaroteño. Esta aceptación de la denominación por parte de los afectados es una prueba concluyente de que el seudogentilicio ha devenido ya en gentilicio inequívoco.

Segunda, que desborda el ámbito designativo de las personas en que lo tenía recluido su antigua condición de seudogentilicio, de calificativo personal, y se extiende también al ámbito designativo de los animales, los vegetales, los minerales, los fenómenos naturales, etc., pertenecientes o relativos al lugar designado y a sus propiedades y atributos, exactamente igual que los gentilicios primarios. Así, como conejero, por ejemplo, no significa ya 'abundante en conejos', sino más concretamente 'perteneciente o relativo a la isla señalada', es evidente que podrá usarse para designar no solamente a las personas que habitan en esa tierra, sino también a sus animales, sus plantas, sus fenómenos atmosféricos, sus productos, etc., como se aprecia en las combinaciones absolutamente normales cabras conejeras, pescado conejero, batatas conejeras, vino conejero, cabildo conejero, capital conejera, etc. Es otra prueba indiscutible de que el proceso de transformación del seudogentilicio en gentilicio se ha consumado definitivamente.

¿Cómo suele evolucionar esta asunción de nuevos sentidos? Lo normal parece ser que el campo de usos del nuevo gentilicio empiece a ampliarse por los atributos pertenecientes o relativos a las personas designadas en primer lugar y que, solo más tarde, se

${ }^{76}$ También los costarricenses ofenden a sus vecinos de Nicaragua reduciendo a nica su denominación gentilicia nicaragüense. Lo peyorativo no se basa ahora en la significación léxica, sino en la significación morfológica, en el acortamiento significante del signo identificador, que aproxima de forma descortés el elemento identificado a la órbita del yo (Morera, 1999: 116). Por el contrario, carece de sentido peyorativo la forma afro, acortamiento del gentilicio africano. 
extienda a los animales, las plantas, los fenómenos naturales, etc., del lugar aludido y a los atributos de estos. Así, en el campo de usos del gentilicio chicharrero, por ejemplo, debieron de aparecer antes combinaciones como habla chicharrera, comida chicharrera, comportamiento chicharrero, industria chicharrera, carnavales chicharreros, etc., que combinaciones como costas chicharreras, cabildo chicharrero, pescado chicharrero, calles chicharreras, etc. Esta expansión semántica es en principio tan incierta, que, en muchos casos, el hablante tiene que aclarar el uso del seudogentilicio añadiendo el gentilicio tradicional. Es lo que se aprecia en el siguiente texto citado por G. Ortega, donde el seudogentilicio gofión, a partir de su designación originariamente personal, empieza a adentrarse también en el ámbito referencial de las cosas, pero tímidamente, apoyado en la muleta del gentilicio canarión, acaso porque el hablante no lo percibe todavía como gentilicio auténtico «Pero hemos llegado al convencimiento de que a nuestros lectores les repugnaría y escandalizaría conocer cómo ha reaccionado la sociedad política canariona y un puñado de maleducados de la calle, varios cientos que conforman el 'simpático mogollón gofión, canarión'» (Ortega Ojeda, 2008: s. v.).

Obviamente, las nuevas acepciones de los gentilicios procedentes de seudogentilicios se comportan exactamente igual que las acepciones de los gentilicios primarios. De un lado, pueden servir de base a ampliaciones designativas secundarias diversas, sea por aplicación metafórica o por desplazamiento metonímico. Ejemplo, el sentido de 'pueblo que instituyó el comunismo' que lleva aparejado hizo que el gentilicio ruso se usara metafóricamente durante la segunda república española para designar a los naturales del pueblo de Almonacid de Toledo, en la provincia de Toledo, por el apoyo que sus habitantes dieron a los partidos de izquierdas ${ }^{77}$. De otro lado, pueden terminar lexicalizándose y dando lugar a nuevos signos descriptivos, con lo que se cierra, obviamente, el proceso de su evolución. Es lo que sucedió con el sentido de 'que roba, saquea, etc.' que sugería secundariamente el gentilicio vándalo (originariamente, 'los que cambian' o 'los hábiles') 'se dice del individuo perteneciente a un pueblo bárbaro de origen germánico oriental procedente de Escandinavia' (al parecer, en origen, 'los que cambian', o 'los hábiles'), que dio como resultado el sustantivo descriptivo español vándalo 'hombre que comete acciones propias de gente salvaje y desalmada'.

Tercera, que adquiera connotaciones nuevas, derivadas de los comportamientos, cualidades, forma de expresarse, hábitos gastronómicos, atuendos, etc., de los individuos designados y de las actitudes que hayan adoptado los demás ante ellos. Así, con el correr del tiempo, el mismo seudogentilicio gaucho, por ejemplo, después de dignificarse convirtiéndose en gentilicio, lo que hizo que perdiera la tupida red de connotaciones negativas que ostentaba (entre ellas, la de 'malintencionado y taimado'), determinadas por su originaria significación léxica de 'borrachín', se cargó de connotaciones altamente positivas, como demuestra la exhaustiva definición que da de él Marcos Morínigo:

Hombre de campo del río de la Plata, jinete por excelencia y especialmente diestro en los trabajos de la ganadería a campo abierto. El gaucho es generalmente pobre, muy sobrio, de pocas necesidades y completamente indife-

${ }^{77}$ Vid. de la Torre Aparicio (2005: 54). 
rente a las comodidades que ofrece la vida civilizada, porque las estima disminuidoras de las virtudes viriles, entre las que está en primer término el valor personal. Como hombre muy seguro de sí mismo, ama su libertad e independencia personal sobre todas las cosas; de estos sentimientos nace su altanería y al mismo tiempo su prudencia. Generoso y leal con los amigos y enemigos, hospitalario en su rancho, lleno de sutil inteligencia y astucia, es también ágil de cuerpo, corto de palabras, cauto para comunicarse con extraños, enérgico en la acción y muy supersticioso [...] (1966: $s . v$.).

De ahí los sentidos secundarios de "dicho de una persona, noble, valiente y generosa' y 'dicho de un animal o de una cosa, que proporciona satisfacción por su rendimiento' con que se emplea el término en Argentina y Uruguay. Se trata de connotaciones que, al contrario que las originarias, no tienen fundamento léxico, sino que tienen fundamento puramente referencial: dependen del mayor o menor prestigio que haya adquirido la gente del lugar designado, en función de su comportamiento, valor, poder, capacidad económica, etc.

Cuarta, que el gentilicio sirva de base para la creación del nombre propio del lugar aludido y que este, a su vez, sirva de base para un nuevo gentilicio. Es lo que sucedió en el caso del antiguo seudogentilicio italo $^{78}$, denominación de una de las viejas etnias de la península italiana. En principio, este gentilicio procedente de seudogentilicio devino en el gentilicio italo. Después, cuando dicha península adquirió conciencia de unidad, sirvió de base para la creación del topónimo Italia, nombre de la patria. Por último, de este último surge, por derivación morfológica, el gentilicio italiano, denominación de los naturales de Italia. Lo mismo parece haber sucedido en el caso de la serie astur $\rightarrow$ Asturias $\rightarrow$ asturiano; en el caso de albano $\rightarrow$ Albania $\rightarrow$ albanés; o en el caso de hispano $\rightarrow$ España $\rightarrow$ español, donde el gentilicio que sirve de base al topónimo (hispano) y el gentilicio que deriva del topónimo (español) presentan incluso sentidos distintos: la forma primitiva hispano significa 'perteneciente o relativo a Hispania', mientras que la forma español significa 'perteneciente o relativo a España'. Así, por un lado, tenemos que son españoles los 'naturales de España', sean antiguos o modernos (pues tan españoles como los castellanos, aragoneses, gallegos, etc., eran los árabes que conquistaron la península durante la edad media, por ejemplo) y que no son españoles los argentinos, venezolanos, peruanos, mejicanos, etc. Por otro, tenemos que son hispanos, los españoles, los argentinos, los venezolanos, los peruanos, los mejicanos, etc., y que no son hispanos los mencionados árabes que conquistaron la península en la edad media. La patria de los españoles es España; la de los hispanos, *Hispana, mucho más amplia que aquella. Una leve ojeada a la lista de gentilicios de países basta para comprobar que, en el origen de los más antiguos de ellos, se encuentra casi siempre una denominación seudogentilicia o en una denominación totémica. Y ello nada tiene de particular por cuanto, como se señaló más arriba, se trata de las denominaciones de «gens» más antiguas que existen.

${ }^{78}$ Según algunos, del nombre viteliu 'ternero' que dieron los oscos o los umbros a las gentes que habitaban la parte meridional de la Calabria, porque tenían como tótem un ternero. 
La coexistencia en un mismo territorio de un gentilicio primario y un gentilicio procedente de seudogentilicio (caso de santacrucero-chicharrero, lanzaroteño-conejero) plantea problemas de gran interés lingüístico y sociolingüístico. Primero, porque el lugar físico designado pasa a tener dos nombres distintos: el que sirve de base al gentilicio primario y el que sirve de base al gentilicio derivado de seudogentilicio. Ejemplo: la capital de la isla de Tenerife, que tiene dos nombres propios (Santa Cruz de Tenerife y El Chicharro) ${ }^{79}$, cada uno de ellos con su gentilicio correspondiente: santacrucero, que significa 'perteneciente o relativo a Santa Cruz', y chicharrero, que significa 'perteneciente o relativo a El Chicharro'. La consecuencia de este planteamiento es que no nos encontramos ante palabras sinónimas, como se suele creer habitualmente Cuando alguien dice que es santacrucero, lo que dice es que está determinado por Santa Cruz, mientras que, si se define como chicharrero, lo que dice es que está determinado por El Chicharro. ¿Que ambos topónimos designan el mismo lugar? Puede ser. Pero significado de forma distinta. Prueba de ello es que ambas palabras presentan evocaciones, valoraciones, sentimientos, etc., distintos. Si se acepta lo dicho, no constituye ningún disparate afirmar que santacruceros y chicharreros viven en dos mundos distintos, si no desde el punto de vista de la geografía física, al menos desde el punto de vista psíquico, sentimental y cultural: El Chicharro es un mundo popular; Santa Cruz, un mundo más formal. Segundo, porque cada una de las dos formas suele presentar prestigio social diferente. Como es natural, el gentilicio primario, considerado denominación oficial, suele tener en principio más prestigio social que el segundo, que se considera denominación oficiosa. En el caso concreto de nuestro ejemplo, santacrucero se considera denominación más formal que chicharrero. No obstante lo dicho, esta situación puede cambiar con el transcurso del tiempo. Así, aunque, con toda seguridad, el gentilicio procedente de seudogentilicio conejero era considerado en principio denominación informal de la gente de Lanzarote, frente a lanzaroteño (o majoreros, como también se les denominaba conjuntamente con los naturales de Fuerteventura), hoy se estima denominación tan formal como esta. Tercero, porque, por lo general, ambas formas suelen librar una guerra más o menos cruenta para quedarse con la función designativa en exclusiva. El resultado de esta pugna resulta siempre incierta: en unos casos, gana la partida el gentilicio primitivo; en otros, el gentilicio procedente de seudogentilicio.

El proceso semántico que comentamos (es decir, la conversión de denominaciones seudogentilicias en denominaciones gentilicias) no constituye tampoco ninguna novedad en el funcionamiento de las lenguas naturales. Se trata exactamente del mismo proceso semántico que llevó a que los nombres comunes españoles cargados de significación léxica $f e$, esperanza, caridad y dolor, por ejemplo, se convirtieran en los nombres propios de persona Fe, Esperanza, Caridad y Dolores, tras vaciarse de su originaria signifi-

${ }^{79}$ De sobra sabido es que los lugares, como toda realidad existente, pueden tener más de un nombre. España, sin ir más lejos, se suele denominar con el término España, pero también con el sintagma nominal Piel de Toro; aunque actualmente la isla de Fuerteventura se denomina Fuerteventura, históricamente también ha recibido las denominaciones de Maxorata, de donde procede su gentilicio majorero, y Herbania; el pueblo de Bustares, en Madrid, se denomina con el nombre oficial de Bustares, pero también con el oficioso de Madridejos de la Sierra; la isla de Tenerife se conoce habitualmente con la denominación de Tenerife, y más raramente con la denominación de Nivaria. 
cación descriptiva de 'en la religión católica, primera de las tres virtudes teologales, asentimiento a la revelación de Dios, propuesta por la Iglesia', 'en la doctrina cristiana, virtud teologal por la que se espera que Dios dé los bienes que ha prometido', 'en la religión cristiana, una de las tres virtudes teologales, que consiste en amar a Dios sobre todas las cosas, y al prójimo como a nosotros mismos' y 'sensación molesta y aflictiva de una parte del cuerpo por causa interior o exterior', respectivamente, y adoptar del contexto una significación mostrativa o identificadora determinada ${ }^{80}$.

De todo lo dicho, se infiere que, aunque gentilicio (signo mostrativo) y seudogentilicio (signo descriptivo) significan la relación entre el hombre y la tierra que este ocupa de forma radicalmente distinta, se trata de procedimientos lingüísticos que pueden y suelen confluir. De sobra sabido es que mostración y descripción no son procedimientos semánticos incompatibles, sino complementarios ${ }^{81}$. Por una parte, el gentilicio, derivado mostrativo que significa al hombre como producto de la tierra (Perú $\rightarrow$ peruano, León $\rightarrow$ leonés), con el paso del tiempo, puede lexicalizarse, y convertirse en nombre absoluto del hombre. En esta nueva situación, puede usarse como denominación seudogentilicia. Por otra, el seudogentilicio, signo léxico que significa de forma absoluta al hombre que ocupa un territorio determinado, señalando alguna característica que le es propia, también con el transcurrir de los años, puede gramaticalizarse, y convertirse en denominación relativa espacial del hombre, es decir, en gentilicio. En esta nueva condición semántica, puede servir de base para la creación del nombre de lugar correspondiente (italo $\rightarrow$ Italia, turco $\rightarrow$ Turquía, hispano $\rightarrow$ España), con lo que introduce un cambio radical en la orientación de la relación entre la tierra y el hombre: mientras que el gentilicio primario significa al hombre como producto de la tierra: el hombre surge de la tierra; el gentilicio procedente de seudogentilicio significa la tierra como producto del hombre: la tierra surge del hombre. Se agotan así las dos orientaciones que puede tener la relación entre el hombre y la tierra: en un caso, se va de la tierra al hombre: el hombre se presenta como el resultado de la naturaleza, el paisaje y la historia de la tierra (corintio, por ejemplo, es el hombre que resulta de nacer de la naturaleza y cultura de Corinto, porque lo que significa es 'lo que emana activamente del concepto Corinto'); en el otro, se va del hombre a la tierra: la tierra se presenta como ámbito dominado por la acción concreta de un hombre que tiene unas determinadas características y que realiza determinadas actividades: Francia, por ejemplo, se entiende como territorio que producen los franceses, porque lo que signifi-

${ }^{80}$ Vid. al respecto Ullmann (1972: 87-88). Antes había dicho Bello que «a veces los nombres apelativos pasan a propios por la frecuente aplicación que se hace de ellos a determinados individuos. Virgilio, Cicerón, César, han sido originalmente nombres apelativos, apellidos que se daban a todas las personas de ciertas familias. Lo mismo ha sucedido con los apellidos castellanos Calderón, Meléndez y muchísimos otros, aun aquellos que significando solar son precedidos de la preposición de, como Quevedo, Alarcón» (1981: 180).

${ }^{81}$ Esta complementariedad entre signos mostrativos y signos descriptivos se observa mejor en el caso de los signos mostrativos polirreferenciales o pronombres, donde hay elementos como nada, cierto, bastante, etc., que fueron originariamente signos descriptivos. 
ca es 'lo (cualidad, potencia, acción, aspiraciones, etc.) que emana activamente del concepto franco', proyectado sobre el espacio ${ }^{82}$.

De esta manera sutil queda trazada una inquietante ecuación idiomática entre el hombre y la tierra, impresa, por lo demás, en la misma etimología del nombre hombre, procedente, como es sabido, del lat. humus 'tierra, suelo, terreno': el hablante sabe, o presiente, que, en la misma medida en que la tierra es tierra porque el hombre la nombra y la conforma con la acción de sus manos laboriosas, su fantasía creadora y su corazón amoroso, o desdeñoso ${ }^{83}$, el hombre es hombre porque hay una tierra que, con su fuerza generadora, lo sustenta y lo moldea física y espiritualmente de una determinada manera, y a la que, más tarde o más temprano, tendrá que rendir cuentas. Nada nuevo bajo el sol, pues, desde antiguo, se viene advirtiendo en la cultura judeocristiana que el hombre es polvo, y, que, como polvo, en polvo nos hemos de convertir ${ }^{84}$. A esto se reduce en esencia el ciclo de la naturaleza: el hombre (también los animales, las plantas, las cosas) se hace tierra con la muerte, y la tierra se hace hombre (también animal, planta, cosa) con la vida.

\section{REFERENCIAS BIBLIOGRÁFICAS}

Academia Canaria de La Lengua (2010): Diccionario básico de canarismos, Islas Canarias, Academia Canaria de la Lengua.

Almeida Costa, J. y A. Sampaio e Melo (1990): Dicionário da língua portuguesa, Porto, Porto Editora.

Alonso, A. (1942): Castellano, español, idioma nacional: historia espiritual de tres nombres, Buenos Aires, Losada.

BARCIA, P. L. (2010): Hacia un diccionario de gentilicios argentinos (DiGA), Buenos Aires, Academia Argentina de Letras.

Bello, A. (1981): Gramática de la lengua castellana, ed. de R. Trujillo, Santa Cruz de Tenerife, Instituto Universitario de Lingüística Andrés Bello.

Benveniste, E. (1970): «Dos modelos lingüísticos de la ciudad», en Problemas de lingüistica general. II, Madrid, Siglo XXI, pp. 274-282.

CASARES, J. (1959): Diccionario ideológico de la lengua española, Barcelona, Gustavo Gili.

CASTRO, A. (2001): España en su historia. Cristianos, moros y judios, Barcelona, Crítica.

Cela, C. J. (1988): Diccionario geográfico popular de España. T. I. Introducción a la Dictalogía Tópica. España, Madrid, NOESIS S. L.

${ }^{82}$ El primero en llamar la atención sobre esta diferencia en la relación del hombre con el lugar que habita fue Benveniste (1970), quien analiza con todo lujo de detalles la diferencia entre el modelo griego polis/polites, que va de la ciudad al ciudadano, y el modelo latino civis/civitas, que va del ciudadano a la ciudad.

${ }^{83}$ San Juan de la Cruz lo dice de forma mucho más bella, en su Cántico: «Mil gracias derramando/ pasó por estos sotos con presura, / y, yéndolos mirando, / con sola su figura / vestidos los dejó de su hermosura».

${ }^{84}$ En este punto, me viene a la memoria la muerte de Pedro Páramo, descrita por Rulfo como desmoronándose en la tierra: «dio un golpe seco contra la tierra y se fue desmoronando como si fuera un montón de piedras». 
Costa, J. (1883-1884): Dictados tópicos (dicterios, elogios, etc.) del Alto Aragón, Badajoz, Diputación de Badajoz.

COSERIU, E. (1977): Principios de semántica estructural, Madrid; Gredos

COVARRUBIAS, S. (1611 [1993]): Tesoro de la lengua castellana o española, ed. de Martín de Riquer, Barcelona, Alta Fulla.

Eliot., T. S. (1968): Función de la poesía y función de la crítica, Barcelona, Seix Barral.

FrAzER, J. C. (2001): La rama dorada, México, Fondo de Cultura Económica.

FREUD, S. (1973): El chiste y su relación con el inconsciente, Madrid, Alianza.

GARCÉS GÓMEZ, M. ${ }^{a}$ P. (1988): «La formación de gentilicios en varias zonas españolas», en Actas del I Congreso de Historia de la Lengua Española, Madrid, Arco/Libros, pp. 1685-1695.

GARcía CABrera, P. (2005): «El hombre en función del paisaje», en Obra selecta, ed. de N. Palenzuela y R. Fernández Hernández, Madrid, Verbum, pp. 18-29.

GARCÍA GALLARÍN, C. (2001): «Los gentilicios recategorizados en apellidos. Contribución al estudio de la influencia norteña en el Madrid de 1600 a 1630», Rivista Italiana di Onomastica, VII, 2, pp. 443-458.

(2003): «Los gentilicios en la historia del español», en Estudios ofrecidos al Profesor José Jesús de Bustos Tovar, ed. de J. L. Girón Alconchel, Madrid, Universidad Complutense, I, pp. 579-598.

GARCÍA PADRÓN, D. (en prensa): «Tipos de alogentilicios y su descripción en los diccionarios académicos españoles», en Avances de Lexicografía, Tarragona.

(en prensa): «La derivación no canónica en los gentilicios españoles», en. G.

Wotjak. D. García Padrón y Mª C. Fumero Pérez, eds., Estudios sobre lengua, cultura y cognición, Frankfurt am Main, Peter Lang.

y M. MORERA, «La descripción lexicográfica de las acepciones de los gentilicios», en V Congreso Internacional de Lexicografia Hispánica, celebrado en la Universidad Carlos III de Madrid, entre los días 25 y 27 de junio de 2012.

HERRERA SANTANA, J. (2012) (en prensa): «La descripción de la competencia comunicativa en los gentilicios de uso no formal en el DRAE-01», en Avances de Lexicografía Hispánica 2 volúmenes, Tarragona.

(en prensa): «Las marcas sociolingüísticas en los gentilicios y su tratamiento lexicográfico», en. G. Wotjak. D. García Padrón y Mª . C. Fumero Pérez, eds., Estudios sobre lengua, cultura y cognición, Frankfurt am Main, Peter Lang.

- y J. M. PÉREZ VIGARAY (en prensa): «El artículo lexicográfico de los sufijos con acepción gentilicia en español: su tratamiento lexicográfico», comunicación presentada en XLI Simposio de la Sociedad Española de Lingüística, celebrado en Valencia, del 31 de enero al 3 de febrero de 2012.

LAPESA, R. (1984): «Sobre el origen de la palabra español», en Estudios de historia lingüistica española, Madrid, Paraninfo, pp. 132-137.

Leite de Vasconcellos, J. (1882): Dictados tópicos de Portugal, colhidos da tradiçáo oral, Barcelos.

LÉVI-STRAUSS, C. (1976): Tristes trópicos, Buenos Aires, EUDEBA.

Machado, A. (1972): Juan de Mairena. Sentencias, donaires, apuntes y recuerdos de un profesor apócrifo (1936), Madrid, Castalia.

MENÉndez PIDAL, R. (2005): Historia de la lengua española, Madrid, Fundación Ramón Menéndez Pidal. 
Morales Pettorino, F., y Ó. Quiroz Mejías (1987): Diccionario ejemplificado de chilenismos. Tomo IV. Per- Z. Suplemento-Bibliografia, Santiago de Chile, Universidad de Playa Ancha de Ciencias de la Educación.

MorerA, M. (1990): Lengua y colonia en Canarias, La Laguna-Tenerife, Globo. (1999): Apuntes para una gramática del español de base semántica. Morfología, Puerto del Rosario, Cabildo de Fuerteventura.

(2000): «Unamuno visto por los majoreros», Cuadernos de la Cátedra Miguel de Unamuno, 35, pp. 95-113.

(2005): La complementación morfológica en español. Ensayo de interpretación semántica, Frankfurt am Main, Peter Lang.

(2005): El habla canaria en la escuela, Puerto del Rosario, Cabildo de Fuerteventura.

(2006): En defensa del habla canaria, Las Palmas de Gran Canaria, Anroart.

(2007a): Español de Canarias e identidad nacional, Puerto del Rosario, Cabildo de Fuerteventura.

(2007b): Todo sobre Canarias. El habla, La Laguna-Tenerife, Centro de la Cultura Popular Canaria.

(2007c): Diccionario histórico-etimológico del habla canaria, Puerto del Rosario, Cabildo de Fuerteventura.

(2007d): «Romanticismo canario e indigenismo», en E. Padorno y G. Santana Henríquez, eds., Lecciones sobre romanticismo canario, Las Palmas de Gran Canaria, Ediciones Clásicas, pp. 83-141.

(2011a): «El gentilicio en español: sus procedimientos expresivos», en M. Morera, El género gramatical en español desde el punto de vista semántico, Frankfurt am Main, Peter-Lang, pp. 95-125.

(2011b): «La norma morfológica de los gentilicios españoles: del topónimo al gentilicio y del gentilicio al topónimo», en E. Waluch-de la Torre, ed., La norma lingüistica del español, Varsovia, Asociación Polaca de Hispanistas, pp. 75-79.

(2012): «El concepto de gentilicio», en M. Campos Souto et al., eds., «Assí com es de suso dicho»: Estudios de morfología y léxico en homenaje a Jesús Pena, San Millán de la Cogolla, Cilengua, pp. 355-364.

(en prensa): «La ampliación designativa de los gentilicios», en G. Wotjak. D.

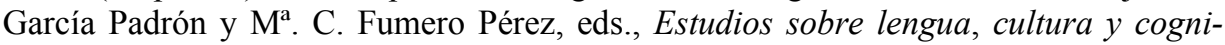
ción, Frankfurt am Main, Peter Lang. ñoles».

y D. GARCÍA PADRÓN (en prensa): «Significado y sentido en los gentilicios espa-

Morínigo, M. (1966): Diccionario de americanismos, Buenos Aires, Muchnik.

NAVArro Artiles, F. (s. f.): Cancionero tradicional de Fuerteventura (inédito).

NIETSZCHE, F. (1988): Ecce homo, Madrid, Ediciones Busma.

NÚÑEZ, L. P. (2005): «La morfología derivativa en los gentilicios en español», Interlingüística, 15, pp. 1047-1056.

OrtegA, G. (2008): Catálogo de los gentilicios canarios, Islas Canarias, Academia Canaria de la Lemgua.

ORTIZ, F. (1985): Nuevo catauro de cubanismos, La Habana, Editorial de Ciencias Sociales.

PADORNO, M. (2011): La palabra iluminada (antología 1955-2007), edición de Alejandro González Segura, Madrid, Cátedra. 
PÉREZ Vigaray, J. M. (en prensa): «Tratamiento lexicográfico de los nombres gentilicios en español», comunicación presentada en el XVI Congreso Internacional de la Asociación de Lingüística y Filología de América Latina (ALFAL), celebrado en Alcalá de Henares, del 6 al 9 de junio de 2011.

RAINER, F. (1999): «La derivación adjetival», en I. Bosque y V. Demonte, dirs., Gramática descriptiva de la lengua española. 3. Entre la oración y el discurso. Morfología, Madrid, Espasa, pp. 4595-4643.

ReAl ACADEMia EsPañola (2001): Diccionario de la lengua española, Madrid, Espasa. (2009): Nueva gramática de la lengua española, Madrid, Espasa.

Rodríguez MoÑInO, A. (1933): Dictados tópicos de Extremadura, Badajoz.

SACHS, G. (1934): «La formación de gentilicios en español», Revista de Filología Española, XXI, pp. 393-399.

SÁNCHEZ AlBORNOZ, C. (1957): España, un enigma histórico, Buenos Aires, EDHASA.

SÁNCHEZ SALAS, G. (2009): La formación de gentilicios, seudogentilicios y otros dictados tópicos en la provincia de Jaén, Barcelona, Ediciones Carena.

SANDRU-OlteANU, T. (1970): «Gentilicios transformados en apelativos en español», en Actele celui de-al XII-ea Congres de Linguistica si Filologie Romanica, Bucarest, Academiei Republicii Romania, I, pp. 973-979.

TORRE APARICIO, T. de la (2005): Diccionario de gentilicios: toponímicos españoles (Incluye: apodos y motes, coplillas, dichos, datos curiosos, etc.), tomo I, Madrid, Visión Net.

TORRIANI, L. (1978): Descripción de las Islas Canarias, traducción del italiano, introducción y notas de Alejandro Ciuranescu, Tenerife, Goya Ediciones.

Tortosa, J. M. (1996): El patio de mi casa, Barcelona, Icaria-Más Madera.

VILLAR, F. (1992): El proceso de autodeterminación del Sáhara, Valencia, Fernando Torres.

Ullmann, S. (1972): Semántica. Introducción a la ciencia del significado, Madrid, Aguilar.

WUNDT, W. (1990): Elementos de psicología de los pueblos, Barcelona, Alta Fulla. 